\title{
Effects of Vegetation and Topography on the Boundary Layer Structure above the Amazon Forest
}

\author{
Marcelo Chamecki, ${ }^{\mathrm{a}}$ Livia S. Freire, ${ }^{\mathrm{b}}$ Nelson L. Dias, ${ }^{\mathrm{c}}$ Bicheng CHen, ${ }^{\mathrm{a}}$ \\ Cléo Quaresma Dias-Junior, ${ }^{\mathrm{d}}$ Luiz Augusto Toledo Machado,,${ }^{\mathrm{e} f \mathrm{f}}$ MATTHias Sörgel, ${ }^{\mathrm{f}}$ \\ ANYwhere TsokANKunku, ${ }^{\mathrm{f}}$ AND Alessandro C. DE ARAújo ${ }^{\mathrm{g}}$ \\ ${ }^{a}$ Department of Atmospheric and Oceanic Sciences, University of California, Los Angeles, Los Angeles, California \\ ${ }^{\mathrm{b}}$ Institute of Mathematics and Computer Sciences, University of São Paulo, São Carlos, Brazil \\ ${ }^{\mathrm{c}}$ Department of Environmental Engineering, Federal University of Paraná (UFPR), Curitiba, Brazil \\ ${ }^{\mathrm{d}}$ Department of Physics, Federal Institute of Pará (IFPA), Belém, Brazil \\ ${ }^{\mathrm{e}}$ Instituto Nacional de Pesquisas Espaciais, Cachoeira Paulista, Brazil \\ ${ }^{\mathrm{f}}$ Atmospheric Chemistry Department, Max Planck Institute for Chemistry, Mainz, Germany \\ ${ }^{\mathrm{g}}$ Empresa Brasileira de Pesquisa Agropecuária, Belém, Brazil
}

(Manuscript received 28 February 2020, in final form 22 June 2020)

\begin{abstract}
Observational data from two field campaigns in the Amazon forest were used to study the vertical structure of turbulence above the forest. The analysis was performed using the reduced turbulent kinetic energy (TKE) budget and its associated two-dimensional phase space. Results revealed the existence of two regions within the roughness sublayer in which the TKE budget cannot be explained by the canonical flat-terrain TKE budgets in the canopy roughness sublayer or in the lower portion of the convective ABL. Data analysis also suggested that deviations from horizontal homogeneity have a large contribution to the TKE budget. Results from LES of a model canopy over idealized topography presented similar features, leading to the conclusion that flow distortions caused by topography are responsible for the observed features in the TKE budget. These results support the conclusion that the boundary layer above the Amazon forest is strongly impacted by the gentle topography underneath.
\end{abstract}

\section{Introduction}

The importance of tower observations in our understanding of turbulence in the lower portion of the atmospheric boundary layer (ABL) can hardly be exaggerated. In addition to advancing our ability to understand turbulence, the deployment of eddy-covariance systems on towers has become the standard method to quantify surface-atmosphere exchanges of momentum, energy, and mass. In particular, the FLUXNET network (Baldocchi et al. 2001; Baldocchi 2008) with over 500 sites is considered the ground truth to assess models and calibrate remote sensing techniques used to infer spatial and temporal patterns of evapotranspiration and carbon fluxes. One particularly difficult problem of great importance is the interpretation of measurements above forests in complex terrain (Lee 1998; Baldocchi et al. 2000). A few field campaigns have been designed with the specific goal of

Corresponding author: Marcelo Chamecki, chamecki@ucla.edu studying forests over complex terrain (Marcolla et al. 2003; Feigenwinter et al. 2010; Arnqvist et al. 2015; Grant et al. 2015; Fernando et al. 2019), and despite significant progress in the development of theory (Finnigan and Belcher 2004; Ross and Vosper 2005; Poggi et al. 2008; Belcher et al. 2012) and the increasing number of studies based on numerical simulations (Ruck and Adams 1991; Ross 2008; Dupont et al. 2008; Patton and Katul 2009; Ross 2011; Chen et al. 2019, 2020), a framework to interpret tower observations over forests in complex topography is still not available.

The focus here is on the central portion of Amazonia, a region of gentle topography covered by a tall and dense forest. Given the fairly small differences in topographic elevation in this region, most of the previous studies interpreted observations in the Amazon based on results and theory for flow over flat topography (Kruijt et al. 2000; Chor et al. 2017; Ghannam et al. 2018; Dias-Júnior et al. 2019), the main exception being the work on day- and nighttime drainage slope flows by Tóta et al. (2012a,b). 
However, the presence of dense vegetation enhances the effect of topography on the flow, such that effects of gentle topography should not be dismissed. In particular, flow separation occurs at much smaller slopes over forested hills than over rough hills (Finnigan and Belcher 2004; Ross and Vosper 2005). Recent largeeddy simulations with real topography for a small region of the Amazon clearly show the occurrence of flow separation in the lee of fairly small hills (Chen et al. 2020).

In this paper we focus on the budget of turbulent kinetic energy (TKE) as a means to understand observations from two field campaigns in different sites in central Amazonia. In particular, we use the reduced TKE budget and its associated phase space introduced by Chamecki et al. (2018) to analyze the two datasets. Chamecki et al. (2018) showed that data above the Amazon forest displayed much larger spread in the reduced TKE phase space than data from the inertial sublayer (ISL) where Monin-Obukhov similarity theory (MOST) is applicable. This spread implies a much larger number of possible states regarding the terms in the TKE budget. However, the authors did not explain the cause for such behavior. In a study using data from a different site in Amazonia, Dias-Júnior et al. (2019) found no evidence of the existence of the inertial sublayer over the Amazon forest. They hypothesized that the canopy roughness sublayer merged directly into the mixed layer, as previously suggested by a schematic figure presented by Malhi et al. (2004). Here we revisit the datasets used by Chamecki et al. (2018) and DiasJúnior et al. (2019), and use the TKE phase space together with LES data to interpret the observations.

\section{Theory}

\section{a. The reduced TKE budget}

We start from the most general form of the TKE budget written as

$$
\begin{aligned}
\underbrace{-\overline{u_{i}^{\prime} u_{j}^{\prime}} \frac{\partial \bar{u}_{i}}{\partial x_{j}}}_{P}+\underbrace{\beta \overline{u_{i}^{\prime} \theta_{v}^{\prime}} \delta_{i 3}}_{B}-\varepsilon= & \frac{\partial \bar{e}}{\partial t}+\underbrace{\bar{u}_{i} \frac{\partial \bar{e}}{\partial x_{i}}}_{-A_{e}}+\underbrace{\frac{\partial \overline{u_{i}^{\prime} e}}{\partial x_{i}}}_{-T_{e}} \\
& +\underbrace{\frac{1}{\rho} \frac{\partial \overline{u_{i}^{\prime} p^{\prime}}}{\partial x_{i}}}_{-\Pi_{e}}=R .
\end{aligned}
$$

In Eq. (1), repeated indices indicate an implicit summation, $e=(1 / 2) u_{i}^{\prime} u_{i}^{\prime}$ so that $\bar{e}$ is the TKE, $\theta_{v}$ is virtual temperature, $\beta=g / \bar{\theta}_{v}$ is the buoyancy parameter, and $\delta_{i j}$ is the Kronecker delta. The terms on the left-hand side of the equation represent local shear production $(P)$, buoyancy production/destruction $(B)$, and the TKE dissipation rate $(\varepsilon)$. The storage term $(\partial \bar{e} / \partial t)$ and all the transport terms that could produce a local imbalance between production and dissipation appear on the right-hand side, and are lumped together into the residual term $(R)$. For convenience, we define the transport terms such that positive values correspond to a local source of TKE. For some terms, this sign convention differs from the usual definition (Stull 1988). The transport terms are the turbulent transport $\left(T_{e}\right)$, the mean advection $\left(A_{e}\right)$, and the pressure transport $\left(\Pi_{e}\right)$. Hereafter we assume that the storage term is negligible and that local imbalance is caused only by transport of TKE.

Following Chamecki et al. (2018), we normalize this "reduced TKE budget" (in which all imbalance terms are lumped together) by the local TKE dissipation rate and write

$$
(P / \varepsilon)+(B / \varepsilon)-1=(R / \varepsilon) .
$$

We use $(R / \varepsilon)$ to diagnose the local TKE budget, noting that $(R / \varepsilon)=0$ represents a state of local balance between production and dissipation of TKE. Positive (negative) values of $(R / \varepsilon)$ are associated with regions in which production is larger (smaller) than dissipation, and we refer to $R$ as the local imbalance term.

To facilitate interpretation of tower observations, it is useful to split $R$ into a vertical component that is consistent with the hypothesis of horizontal homogeneity $\left(R^{v}\right)$ and a horizontal component caused by deviations from that state $\left(R^{h}\right)$. Under stationary and horizontally homogeneous conditions, the second equation in (1) reduces to

$$
R^{v}=-T_{e}^{v}-\Pi_{e}^{v}=\frac{d \overline{w^{\prime} e}}{d z}+\frac{1}{\rho} \frac{d \overline{w^{\prime} p^{\prime}}}{d z} .
$$

Thus, we can write

$$
R^{h}=R-R^{v}=R+T_{e}^{v}+\Pi_{e}^{v},
$$

and utilize $R^{h} / \varepsilon$ as a measure of the importance of horizontal heterogeneity on the TKE budget. The pressure transport term is always a difficult issue in the analysis of the TKE budget, as it is usually not directly measured (Wyngaard 2010). For horizontally homogeneous flows in the convective boundary layer, the pressure transport term is typically smaller than the dominant terms in the budget (Lenschow et al. 1980). For flow above canopies, LES results suggest that the pressure transport term has the same sign as the turbulence transport but with much smaller magnitude (Dwyer et al. 1997). Given the lack of reliable measurements and the likely smaller role 

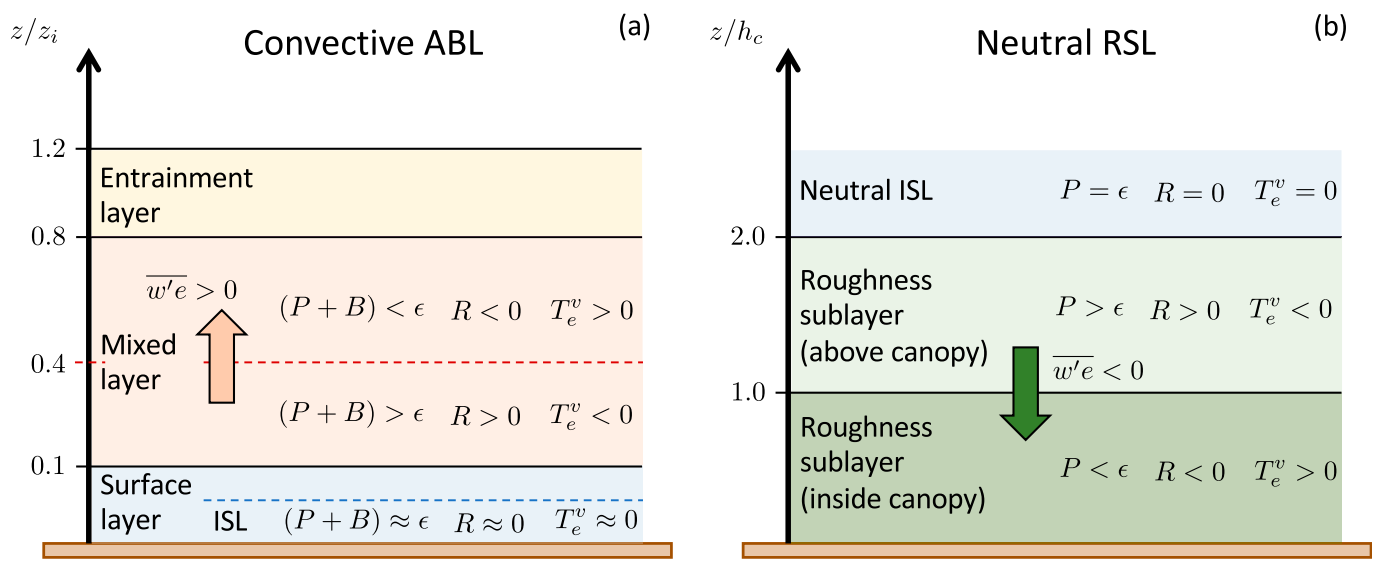

FIG. 1. Sketch of idealized TKE budgets (a) in the convective ABL over a rough surface and (b) in the neutral canopy roughness sublayer. Both scenarios are depicted under the assumption of horizontal homogeneity $\left(R^{h}=0\right)$ and neglecting the pressure transport term $\left(\Pi_{e}^{v} \approx 0\right)$. In (a), the blue dashed line separates the inertial sublayer (ISL) from the matching layer above (note that in less convective conditions there is no matching layer and the dashed line coincides with $\left.z / z_{i}=0.1\right)$. The red dashed line indicates the height where $(P+B)=\varepsilon$, separating the mixed layer in a region with more production than dissipation below the line from a region with less production than dissipation above it.

of pressure transport in horizontally homogeneous conditions, hereafter we exclude it from our discussions, effectively assuming $T_{e}^{v} \gg \Pi_{e}^{v}$ and thus $R^{h} \approx R+T_{e}^{v}$.

\section{b. Structure of daytime ABL over forests}

The classic structure of the convective boundary layer (CBL) over horizontally homogeneous rough surfaces comprises three main layers (see Fig. 1a): the surface layer $\left(z / z_{i} \leq 0.1\right)$, the mixed layer $\left(0.1 \leq z / z_{i} \leq 0.8\right)$, and the entrainment layer $\left(0.8 \leq z / z_{i} \leq 1.2\right)$, where $z_{i}$ is the CBL height. Numbers in parenthesis are just a rough estimate of the region occupied by each layer. In terms of the TKE budget, we expect a state of approximate local balance between production and dissipation within the surface layer (i.e., $R \approx 0$ ). As shown by Chamecki et al. (2018), MOST functions imply production slightly smaller than dissipation across the range of stability. Note that MOST is only applicable in a portion of the surface layer, in which the details of the surface roughness are no longer relevant (i.e., $z \gg z_{0}$, where $z_{0}$ is the surface roughness length) and the friction velocity is the appropriate velocity scale. The latter is usually considered to be true as long as $z /\left|L_{o}\right| \leq 2$, where $L_{o}$ is the Obukhov length. Under more convective conditions (i.e., when $z / L_{o}<2$ ), in the matching layer, the local free-convection velocity becomes the appropriate velocity scale (Kaimal and Finnigan 1994). To facilitate things, we refer to the entire layer $z / z_{i} \leq 0.1$ as the surface layer, and reserve the term ISL to the portion where the log law is applicable in neutral conditions and MOST is expected to hold in nonneutral cases (below the blue dashed line in Fig. 1a).
Above the surface layer, production is larger than dissipation in the lower part of the mixed layer $(R>0)$ and production is smaller than dissipation in the upper portion $(R<0)$. This separation is indicated by the red dashed line in Fig. 1a. Thus, in idealized homogeneous conditions, the excess of TKE produced in the lower half of the CBL is exported (mostly) by turbulent transport to the upper half of the CBL, where it is dissipated. Aircraft measurements by Lenschow et al. (1980) show that indeed $\overline{w^{\prime} e}>0$ within the ABL (i.e., the flux of TKE is directed upward) and suggest that the change in the sign of the turbulent transport $\left(T_{e}^{v}\right)$ occurs at $z / z_{i} \approx 0.4$.

In the presence of a vegetation canopy such as a forest, the TKE budget in the surface layer is significantly modified by the vegetation, giving rise to the roughness sublayer (RSL). In the region inside and just above the canopy, the canopy height $h_{c}$ is adopted as the appropriate length scale. As sketched in Fig. 1b, in the neutrally stratified $(B=0) \mathrm{RSL}$, production is larger than dissipation above the canopy (and in the uppermost region inside the canopy) and the imbalance term is positive. The excess of energy is transported by turbulence into the (lower) canopy, where local production is smaller than dissipation (Brunet et al. 1994), implying a negative imbalance $(R<0)$. Thus, turbulent transport is negative above the canopy and positive within the canopy, with a downward flux of TKE (Fig. 1b). These modifications of the TKE budget extend up to $z / h_{c} \approx 2$, where the local equilibrium between production and dissipation is reestablished and the RSL blends into a classical inertial sublayer in which the log law is valid (Kaimal and Finnigan 1994; Pan and Chamecki 2016). 
This limit for the top of the RSL is consistent with the usual range adopted in the literature between $z / h_{c}=2$ and $z / h_{c}=3$ (Harman and Finnigan 2007), and it is also consistent with the empirical value $z / h_{c} \approx 2.2$ based on the enhancement of eddy diffusivities for heat and water vapor (Cellier and Brunet 1992). If we extend this picture to unstable conditions, MOST would be valid above $z / h_{c} \approx 2$ as well (Cellier and Brunet 1992).

Thus, for convective conditions above a forest, the existence of an ISL where MOST is applicable is bounded below by the RSL, and above by the mixed layer or the matching layer. In the application of MOST above a canopy, the vertical origin is placed at a distance $d_{0}$ from the ground, which is defined as the mean level of momentum absorption by the canopy (Jackson 1981) and is termed the displacement height. Thus, a point in the ISL must satisfy simultaneously three criteria: (i) $\left(z-d_{0}\right) / z_{i} \leq 0.1$, (ii) $\left(z-d_{0}\right) /\left|L_{o}\right| \leq 2$, and (iii) $z \geq 2 h_{c}$. In free convection with a regime dominated by convective cells, $z_{i} /\left|L_{o}\right|>20$ (Salesky et al. 2017), condition (ii) is more restrictive than condition (i). Conversely, in forced convection with a regime dominated by rolls, condition (i) is more restrictive. As first hypothesized by Malhi et al. (2004) and later discussed by Dias-Júnior et al. (2019), it is possible that the ISL does not exist above tall forests. Here we can quantify this assertion by assessing if there exists a height $z$ such that all three conditions are simultaneously satisfied. Combining the three criteria above, the existence of an inertial layer in which MOST is valid is only possible if the following two derived conditions are simultaneously satisfied:

$$
\begin{aligned}
h_{c} /\left|L_{o}\right| & \ll 2 /(2-\alpha), \\
h_{c} / z_{i} & \ll 0.1 /(2-\alpha),
\end{aligned}
$$

where $\alpha=d_{0} / h_{c}$. Thus, for fixed atmospheric conditions (given by $L_{o}$ and $z_{i}$ ), there is a maximum canopy height that allows an ISL to exist. Usual values of $\alpha$ are in the range $(2 / 3) \leq \alpha \leq(3 / 4)$, and for $\alpha=0.7$ the two criteria for the existence of an ISL become $h_{c} \ll$ $\min \left\{1.5\left|L_{o}\right|, 0.08 z_{i}\right\}$.

\section{Methods}

\section{a. Observational data}

The main focus of this study is the analysis of data from two field campaigns designed to measure turbulence above the Amazon forest: the GoAmazon campaign, which took place from March 2014 through January 2015 at the Cuieiras Biological Reserve (Fuentes et al. 2016; Freire et al. 2017), and the Amazon Tall Tower Observatory (ATTO)-IOP1 (Oliveira et al. 2018; Dias-Júnior et al. 2019) during October/November 2015 at the Uatumã Sustainable Development Reserve. The locations of the towers at the two sites are shown over a topographic map in Fig. 2. Both sites are located at plateaus and, given the predominance of easterly winds in the region, nearby valleys in the east-west direction were used to characterize the local topography (Figs. 2d,e). Thus, the GoAmazon K34 tower (located at $2.602^{\circ} \mathrm{S}, 60.209^{\circ} \mathrm{W}$; see Figs. 2b,d) sits on a hill with height $H_{h} \approx 50 \mathrm{~m}$ and horizontal length $4 L_{h} \approx 1.5 \mathrm{~km}$, where $L_{h}$ is the horizontal half-length of the topography (Finnigan and Belcher 2004). This geometry corresponds to an average slope of approximately $H_{h} /\left(2 L_{h}\right) \approx 0.07$. The ATTO towers (located at $2.146^{\circ} \mathrm{S}, 59.006^{\circ} \mathrm{W}$ and $2.144^{\circ} \mathrm{S}, 59.000^{\circ} \mathrm{W}$; see Figs. $\left.2 \mathrm{c}, \mathrm{e}\right)$ are located on a hill with height $H_{h} \approx 70 \mathrm{~m}$ and horizontal length $4 L_{h} \approx 2.25 \mathrm{~km}$, with average slope $H_{h} /\left(2 L_{h}\right) \approx$ 0.06 . The canopy height at the GoAmazon and ATTO sites were estimated to be $h_{c}=35 \mathrm{~m}$ (Fuentes et al. 2016) and $h_{c}=37 \mathrm{~m}$ (Oliveira et al. 2018), respectively.

On both field campaigns, vertical arrays of sonic anemometers were deployed on tall towers with the goal of profiling turbulence within and above the canopy. Only measurements obtained above the forest $\left(z / h_{c} \geq 1\right)$ were used here. In the GoAmazon campaign, nine sonic anemometers were deployed on a 50-m tower (K34), with three being above canopy top. On the ATTO campaign, eight sonic anemometers were deployed on two towers (a 80-m tower and the 325-m-tall tower) located $670 \mathrm{~m}$ apart, five of them being above the canopy. See Table 1 for more information about the sensors employed here.

The data processing strategy was designed to ensure the use of high-quality data without excessively reducing the amount of data available for analysis. Due to the short measurement period of the ATTO IOP campaign, less restrictive criteria had to be applied. Data processing procedures are briefly outlined here. (i) Data were separated into blocks of $30 \mathrm{~min}$ starting at 0000 local time. Up to $1 \mathrm{~s}$ of consecutive missing data were replaced by previous measurements, whereas blocks with more than $1 \mathrm{~s}$ of missing data were discarded. For the ATTO data only, the first $2 \mathrm{~min}$ of each block were also discarded, as they were mostly missing data due to technical issues with data transfer (so the blocks are effectively $28 \mathrm{~min}$ long). (ii) Blocks were selected according to the direction of mean wind. For GoAmazon, the criterion corresponded to mean wind at the highest anemometer within $\pm 90^{\circ}$ from the anemometer axis (the mean wind direction difference between anemometers is small due to the small height separation). For the ATTO, data with mean wind within $\pm 135^{\circ}$ for each individual anemometer were selected. (iii) On the remaining data, a planar fit (Wilczak et al. 2001) was performed to correct for instrument tilting. (iv) Blocks with negative heat flux 


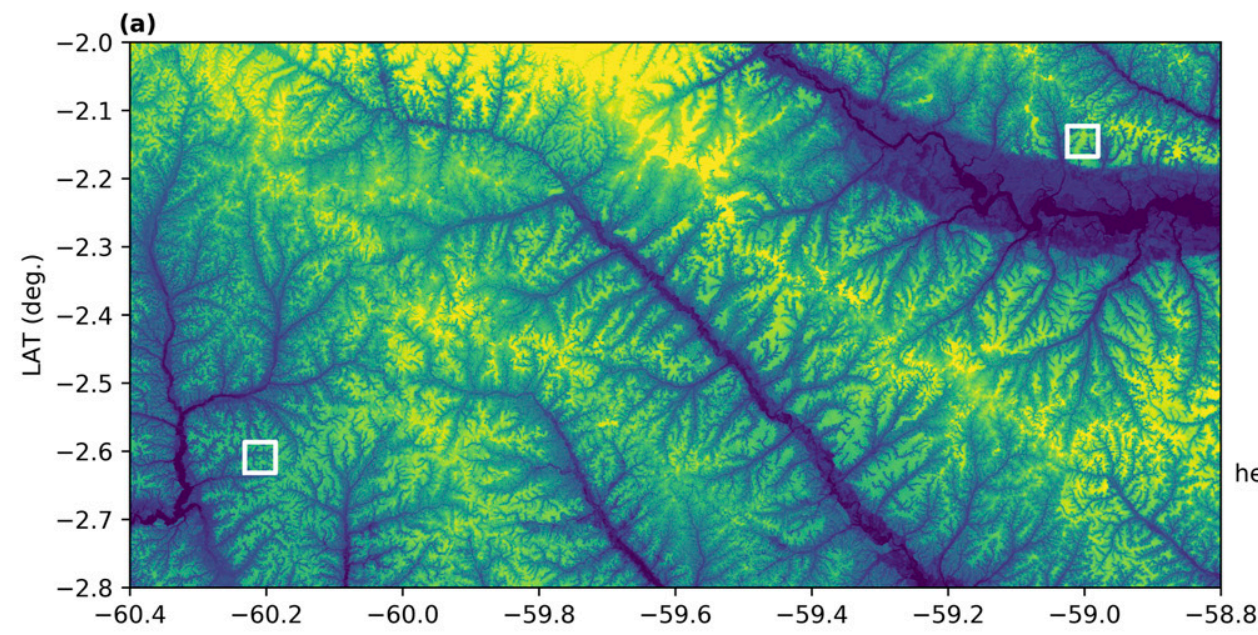

(b)
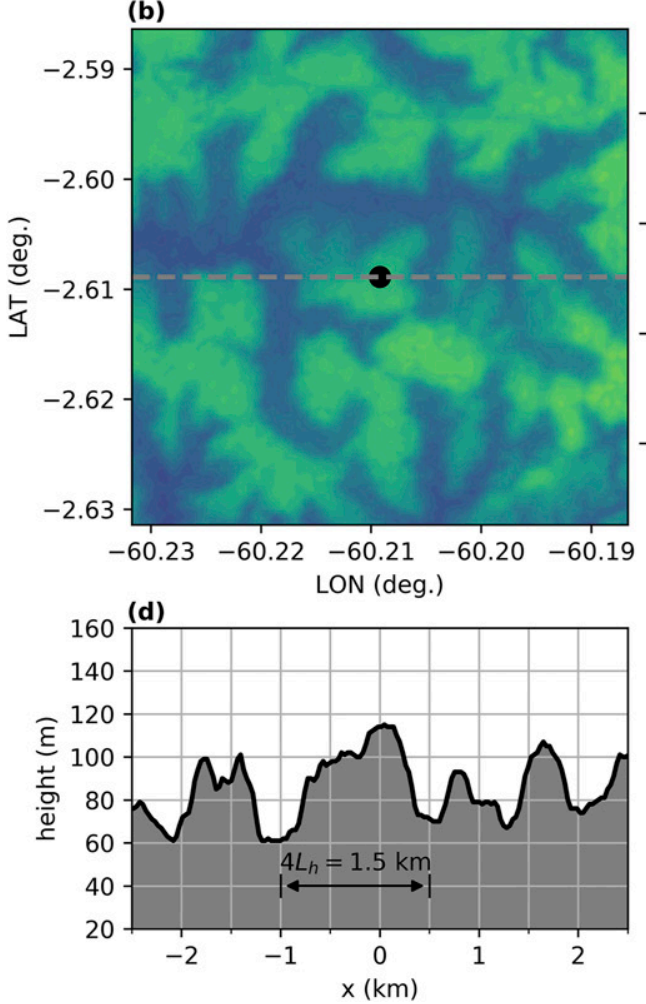

(c)
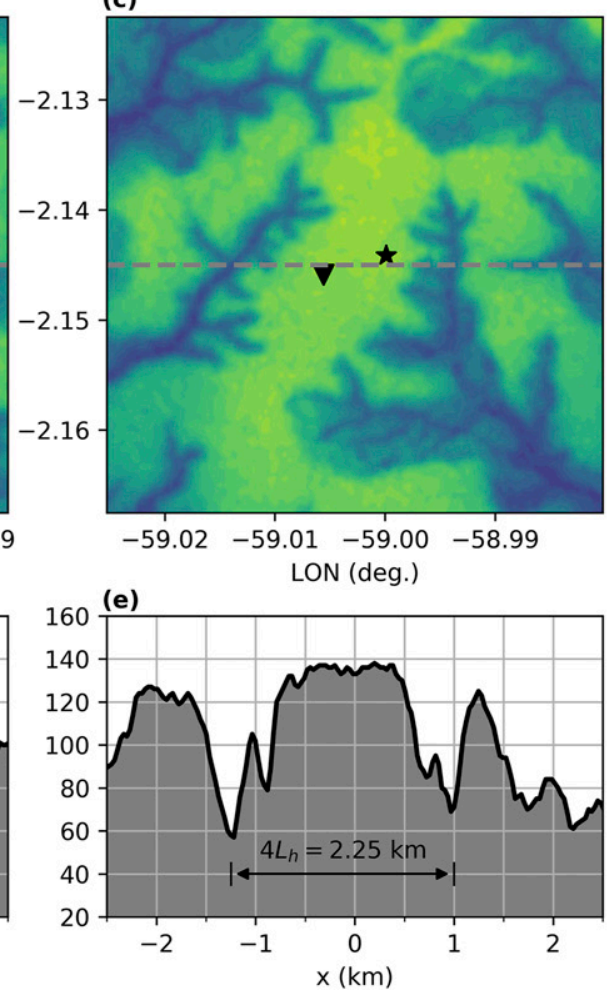

FIG. 2. (a) Topography map of a portion of central Amazonia, including the locations of the GoAmazon field campaign (left white square) and the ATTO field campaign (right white square). (b) Zoomed-in view of the left white square in (a). The black circle in (b) marks the location of the K34 tower $\left(2.602^{\circ} \mathrm{S}, 60.209^{\circ} \mathrm{W}\right)$. (c) Zoomed-in view of the right white square in (a). The triangle and star in (c) mark the locations of the tall tower $\left(2.146^{\circ} \mathrm{S}\right.$, $\left.59.006^{\circ} \mathrm{W}\right)$ and the walk-up tower $\left(2.144^{\circ} \mathrm{S}, 59.000^{\circ} \mathrm{W}\right)$, respectively. (d), (e) Cuts through the topography along the gray dashed lines indicated in (b) and (c),respectively, indicating the adopted horizontal lengths $4 L_{h} \approx 1.5 \mathrm{~km}$ for the GoAmazon and $4 L_{h} \approx 2.25 \mathrm{~km}$ for the ATTO sites. Data obtained from the 30 -m-resolution SRTM (Farr et al. 2007).

(measured at the top of the canopy for the GoAmazon and at individual anemometers at ATTO) were filtered with a 3-min top-hat high-pass filter (i.e., a centered moving average) to remove nonturbulent oscillations usually present in stably stratified conditions (Mahrt 2014). This filtering had almost no effect on the results presented here, as the focus is on unstable conditions. (v) The stationarity criteria for the horizontal wind 
TABLE 1. Sonic anemometer data.

\begin{tabular}{ccccccc}
\hline \hline Site & Tower height $(\mathrm{m})$ & Sonic height $(\mathrm{m})$ & $z / h_{c}$ & \multicolumn{1}{c}{ Model } & Frequency $(\mathrm{Hz})$ & No. of blocks \\
\hline GoAmazon $\left(h_{c}=35 \mathrm{~m}\right)$ & 50 & 34.9 & 1.00 & CSAT3 $^{\mathrm{a}}$ & 20 & 319 \\
& 50 & 40.4 & 1.15 & CSAT3 & 20 & 292 \\
& 50 & 48.2 & 1.38 & CSAT3 & 20 & 238 \\
ATTO $\left(h_{c}=37 \mathrm{~m}\right)$ & 80 & 41 & 1.08 & CSAT3 & 10 & 103 \\
& 80 & 55 & 1.49 & CSAT3 $^{2}$ & 10 & 120 \\
& 80 & 80 & 2.20 & Windmaster $^{\mathrm{b}}$ & 10 & 111 \\
& 325 & 150 & 4.06 & CSAT3 $^{\mathrm{a}}$ & 10 & 84 \\
& 325 & 325 & 8.78 & IRGASON $^{\mathrm{a}}$ & 20 & 45 \\
\hline
\end{tabular}

${ }^{\text {a }}$ Campbell Scientific, Inc.

${ }^{\mathrm{b}}$ Gill Instruments Limited

proposed by Vickers and Mahrt (1997) were used, and blocks with nonstationarity ratios $\mathrm{RNu}, \mathrm{RNv}$ and RNS $\geq 0.5$ were discarded (here $\mathrm{RNu}=\delta u / \bar{u}$ is the nonstationarity ratio for the streamwise velocity component, with $\delta u$ being the difference in streamwise velocity at the beginning and end of the block obtained from a linear regression; $\mathrm{RNv}=\delta v / \bar{u}$ and $\mathrm{RNS}=\sqrt{\delta u^{2}+\delta v^{2}} / \bar{u}$ are nonstationarity ratios for the crosswise wind component and the horizontal wind vector, respectively). The remaining blocks were used for data analysis.

The terms in the TKE budget were calculated under the usual assumption of horizontal homogeneity over flat terrain. Shear production was calculated from $P=-\overline{u^{\prime} w^{\prime}}(d \bar{u} / d z)$, with the mean velocity gradient estimated from a second-order polynomial fit in $\ln (z)$ (Högström 1988). For the GoAmazon data, this fit included a fourth anemometer at $z / h=0.90$ [see Freire et al. (2019a) for more details]. Buoyancy production was calculated from $B=\left(g / \bar{\theta}_{v}\right) \overline{w^{\prime} \theta_{v}^{\prime}}$. The flux Richardson number $\mathrm{Ri}_{f}=-B / P$ was used to characterize atmospheric stability. When assessing applicability of MOST, the Obukhov length $L_{o}=-u_{*}^{3} /(\kappa B)$ was estimated from the buoyancy production at canopy top ( $\kappa$ is the von Kármán constant). Dissipation rates were obtained from the theoretical prediction for the inertial subrange of the second-order structure function $\overline{\Delta u^{2}}=C_{2}(r \varepsilon)^{2 / 3}$ (Kolmogorov 1941) using the approach outlined by Chamecki and Dias (2004). The range of scales that conformed most closely to inertial subrange behavior was $0.5 \leq r \leq 2 \mathrm{~m}$ for the GoAmazon and $1 \leq r \leq 5 \mathrm{~m}$ for ATTO, and these ranges were used together with $C_{2}=$ 1.97 in the estimates. We note that dissipation rates obtained from the energy spectrum were $24 \%$ larger, likely due to aliasing effects (Freire et al. 2019b), and values obtained from structure function were considered more reliable as structure functions are not impacted by aliasing errors (using dissipation rates from the spectrum would not have affected the conclusions of this study). The vertical turbulent transport of TKE was calculated from $T_{e}^{v}$ by fitting a second-order polynomial in $z$ (GoAmazon) and $\log (z)$ (ATTO) to the vertical flux of TKE $\left(\overline{w^{\prime} e}\right)$. From these terms of the TKE budget, the local imbalance and its nonhomogeneous portion were calculated from $R=(P+B-\varepsilon)$ and $R^{h} \approx R+T_{e}^{v}$.

After data analysis, a few criteria were employed to further select blocks used in the calculation of statistics. (i) Blocks were selected for the existence of an inertial subrange in the second-order structure function with slope within $\pm 10 \%$ (GoAmazon) and $\pm 20 \%$ (ATTO) of the theoretical value of $2 / 3$ (Kolmogorov 1941). (ii) Blocks from the GoAmazon data with very small values of TKE dissipation rate $\left(\varepsilon \leq 5 \times 10^{-5} \mathrm{~m}^{2} \mathrm{~s}^{-1}\right)$ or with negative shear production were eliminated (for the ATTO data, no blocks had small dissipation and negative shear production only occurred in buoyancydominated conditions). (iii) Because the focus here is on convective conditions, blocks with stable conditions were also eliminated (here $R i_{f}>0.04$ was used). (iv) Finally, blocks from ATTO when $z_{i}$ was below the highest anemometer were also discarded. The final number of blocks used hereafter is shown in Table 1.

Vertical profiles of momentum flux inside the canopy from the GoAmazon field campaign were also used to determine the displacement height (Jackson 1981), yielding $\alpha=d_{0} / h_{c} \approx 0.78$. A rough estimate of roughness length scale $z_{0} / h_{c} \approx 0.06$ was also obtained from $\bar{u}_{h_{c}}=\left(u_{*} / \kappa\right) \ln \left[\left(h_{c}-d_{0}\right) / z_{0}\right]$. Estimates of ABL height $z_{i}$ were obtained from ceilometer data (Jenoptik CHM15k) collected during the ATTO field campaign [see DiasJúnior et al. (2019) for more details]. The ABL height estimates obtained by Dias-Júnior et al. (2019) were about $25 \%$ smaller than those obtained from the global reanalysis product ERA5, but were consistent with other observations above the Amazon forest (Fisch et al. 2004). ABL heights play a small role in our data analysis and, in the only figure in which they are employed, we are being conservative in using the smaller values obtained by Dias-Júnior et al. (2019). 
TABLE 2. Setup used in the three numerical simulations.

\begin{tabular}{lccc}
\hline \multicolumn{1}{c}{ Variable } & LES_CBL & LES_FOR & LES_TOPO \\
\hline Domain size $\left(L_{x} \times L_{y} \times L_{z} ; \mathrm{m}\right)$ & $7680 \times 7680 \times 2700$ & $2000 \times 1000 \times 520$ & $2000 \times 1000 \times 540$ \\
Grid size $\left(\Delta_{x} \times \Delta_{y} \times \Delta_{z} ; \mathrm{m}\right)$ & $30 \times 30 \times 6.75$ & $6.25 \times 6.25 \times 2.00$ & $6.25 \times 6.25 \times 2.00$ \\
Grid points $\left(N_{x} \times N_{y} \times N_{z}\right)$ & $256 \times 256 \times 400$ & $320 \times 160 \times 260$ & $320 \times 160 \times 270$ \\
Pressure gradient force $\left(\mathrm{m} \mathrm{s}^{-2}\right)$ & $6.125 \times 10^{-4} \mathrm{a}$ & $3.11 \times 10^{-4}$ & $3.11 \times 10^{-4}$ \\
Coriolis frequency $\left(\mathrm{s}^{-1}\right)$ & $1 \times 10^{-4}$ & 0 & 0 \\
Surface heat flux $\left(\mathrm{km} \mathrm{s}^{-1}\right)$ & $3.76 \times 10^{-2}$ & 0 & 0 \\
ABL height $(\mathrm{m})$ & 1570 & 515 & 515 \\
\hline
\end{tabular}

${ }^{\text {a }}$ Applied in the negative $y$ direction based on a geostrophic velocity of $U_{g}=5 \mathrm{~m} \mathrm{~s}^{-1}$.

Finally, we also used tower data collected over a flat grass field during the Advection Horizontal Array Turbulence Study (AHATS) field campaign (Earth Observing Laboratory 1990; Salesky and Chamecki 2012) to illustrate typical ISL behavior. For more information about the data processing, see Chamecki et al. (2017, 2018).

\section{b. Numerical data}

We employed data from three LES runs to aid the interpretation of field observations from the Amazon forest. To illustrate the behavior of the CBL on the TKE phase space, we used one simulation from Chor et al. (2020, manuscript submitted to J. Atmos. Sci.) of a horizontally homogeneous $\mathrm{CBL}$ over a rough and flat surface with $z_{i} /\left|L_{o}\right| \approx 37\left(L_{o}=-41.23 \mathrm{~m}\right)$. More information about the simulation setup can be found in Table 2.

In addition, we used two simulations with a model canopy for the Amazon forest from Chen et al. (2019), one over flat terrain and the other one over a sinusoidal ridge with amplitude $H_{h}=50 \mathrm{~m}$, wavelength $4 L_{h}=$ $1.0 \mathrm{~km}$, and average slope $H_{h} /\left(2 L_{h}\right) \approx 0.10$, which was considered representative of Amazon topography (these simulations were referred to S0.0 and S0.2 in the original paper). In the simulation with topography, the mean flow was perpendicular to the ridges and the flow was homogeneous in the crosswise direction.

Averages were calculated in time and directions of homogeneity, and fluctuations were defined with respect to these averages. Because the terms on the TKE budget are independent of the frame of reference adopted, data analysis was carried in the original cartesian coordinate system for all simulations (note that decomposition of terms into horizontal and vertical components such as $R=R^{h}+R^{v}$ do depend on the choice of coordinate system, but these decompositions were not applied to the LES data). In the simulation with topography, shear production was calculated using all terms in the definition given in Eq. (1). In all simulations the subgridscale (SGS) dissipation rate $\varepsilon_{\mathrm{sgs}}=-\left\langle\tau_{i j} \tilde{S}_{i j}\right\rangle$ was used as a proxy for the TKE dissipation rate (here $\tau_{i j}$ is the SGS stress tensor, $\tilde{S}_{i j}$ is the resolved strain rate tensor, and angle brackets $\langle\cdot\rangle$ represent averaging in time and over directions of homogeneity).

\section{Results}

\section{a. Convective $A B L$ and the roughness sublayer}

We used the AHATS observations to establish the typical pattern of measurements within the ISL (where MOST is applicable) on the TKE phase space (Fig. 3a). As shown by Chamecki et al. (2018), AHATS data occupied a small portion of the phase space, scattering around the line of local balance between production and dissipation $(R \approx 0)$. Ensemble averages conditioned on values of the stability parameter $\left(-z / L_{o}\right)$ are also shown, displaying slightly negative local imbalance $(R<0)$ and implying total production slightly smaller than dissipation within the ISL. This result is in agreement with the behavior implied by empirical functions obtained from MOST (Businger et al. 1971; Högström 1988, 1990), as discussed in more detail in Chamecki et al. (2018).

To complement this picture, results from the two LES runs for flat terrain are displayed together in Fig. 3b. The simulation of a convective ABL over a rough surface showed slightly positive imbalance within the ISL, which extended up to $z / L_{o} \approx-2$ (spanning the range between the " + " and " $X$ " markers in Fig. 3b). Beyond this point, the local imbalance increased significantly, marking a clear departure from ISL behavior. As expected from the large value of $z_{i} /\left|L_{o}\right|$, the ISL did not extend up to $z / z_{i}=0.1$ (marked by a " $\bigcirc$ " marker in Fig. 3b). Above the ISL, the local imbalance increases with height, reaching a maximum of $R / \varepsilon \approx 0.52$ at $z / z_{i} \approx 0.18$. A state of local balance between production and dissipation was reached at $z / z_{i} \approx 0.5$, and the local imbalance became markedly negative in the upper part of the mixed layer. These results are consistent with Fig. 1a and with aircraft measurements by Lenschow et al. (1980) suggesting that the change in the sign of turbulent transport occurs at 

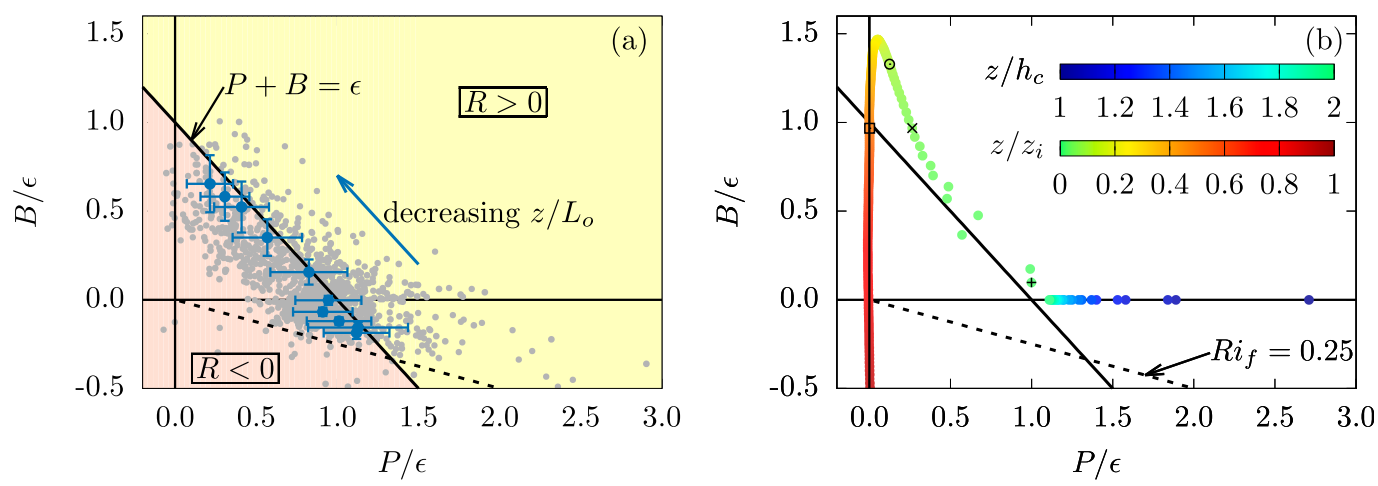

FIG. 3. Reduced TKE phase space for (a) the AHATS ISL data and (b) simulations of a CBL and a neutral roughness sublayer. In (a) the yellow and orange regions correspond to $R>0$ and $R<0$, respectively, and the line indicated by $P+B=\varepsilon$ corresponds to $R=0$ (the local imbalance $R / \varepsilon$ for any point in the phase space is proportional to its distance to this line). The symbols in (b) indicate the first grid point of the LES ( + at $\left.z / z_{i}=0.002\right)$, the top of the $\operatorname{ISL}\left(\times\right.$ at $z_{i} /\left|L_{o}\right|=2$, which for this case occurs at $\left.z / z_{i} \approx 0.05\right)$, the top of the surface layer $\left(\bigcirc\right.$ at $\left.z / z_{i}=0.1\right)$, and the point where $\mathrm{R}$ becomes negative $\left(\square\right.$ at $\left.z / z_{i} \approx 0.5\right)$.

$z / z_{i} \approx 0.4$. It is possible that the height where this change in the local imbalance sign occurs is influenced by the stability of the ABL (i.e., it may actually depend on $\left.z_{i}|| L_{o} \mid\right)$.

Finally, we used the simulation of a neutral ABL over a model of the Amazon forest to assess the effects of a horizontally homogeneous canopy on the patterns in the TKE phase space. Because the simulation had neutral stratification, all points were constrained to be on the line $B / \varepsilon=0$. At the canopy top $R / \varepsilon$ was very large $(R / \varepsilon>2.5)$, indicating that shear production was much larger than dissipation. The imbalance reduced with increasing distance from the canopy top, being almost zero at $z / h_{c}=2$, in agreement with wind tunnel measurements by Brunet et al. (1994) and numerical simulations by Pan and Chamecki (2016). Thus, from the perspective of the TKE budget, the top of the roughness sublayer was located at $z / h_{c} \approx 2$.

The superposition of the two simulations in Fig. $3 b$ is an idealization, which can be interpreted as a continuum by assuming that buoyancy effects are negligible within the RSL (i.e., $h_{c} /\left|L_{o}\right| \ll 1$ ) and that the RSL only occupies the bottom of the surface layer (i.e., $h_{c} / z_{i} \ll 0.1$ ). We used this superposition as a starting point to infer patterns in the phase space that would have occurred for larger canopy height $h_{c}$ under the same atmospheric conditions (characterized by $z_{i}$ and $L_{o}$ ). For practical purposes, we considered cases in which $z_{i}|| L_{o} \mid>20$, so that the surface layer was split into an ISL and a matching layer. Two main cases are of interest here. In case " $\mathrm{C} 1, " h_{c}$ was increased enough that buoyancy modified turbulence in the RSL, but the criteria for the existence of an inertial layer [Eqs. (5) and (6)] were still satisfied. The expected behavior of the reduced TKE budget is represented by curve "C1" in Fig. 4, indicating the existence of an ISL (characterized by an approximate local balance between production and dissipation) above the RSL. MOST is expected to be applicable within this elevated ISL. A further increase in $h_{c}$ would cause the criterion (5) to be violated and the RSL would merge directly into the matching layer as indicated by the curve "C2." In the latter case, the ISL does not exist. Malhi et al. (2004) suggested that both cases are possible in the surface layer above the Amazon forest, and DiasJúnior et al. (2019) concluded that the absence of a layer that followed MOST in the observations from the ATTO tower might have been caused by the behavior described by curve "C2." A critical point in Fig. 4 is that,

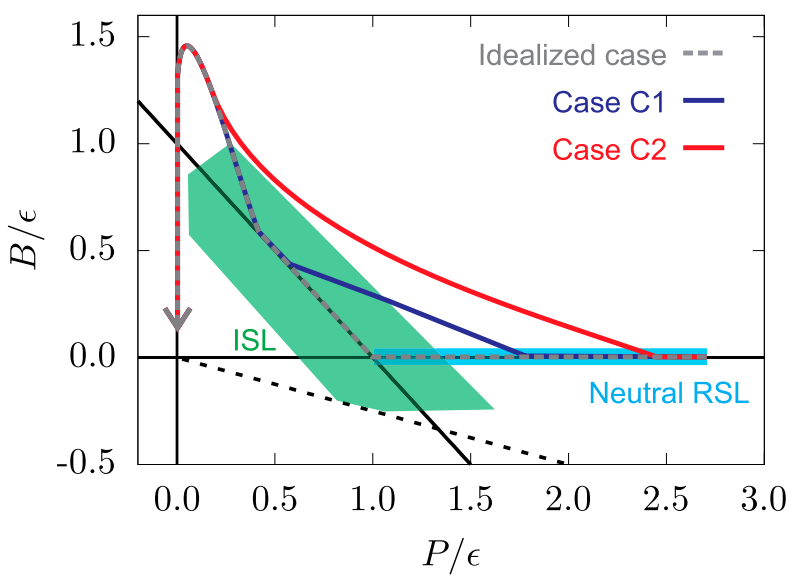

FIG. 4. Sketch showing expected behavior of cases "C1" and "C2" on the TKE phase space. In case "C1," the canopy is tall enough for the RSL to be impacted by buoyancy, but an ISL still exists above the RSL. In case "C2," the RSL merges directly into the matching layer and an ISL does not exist. 

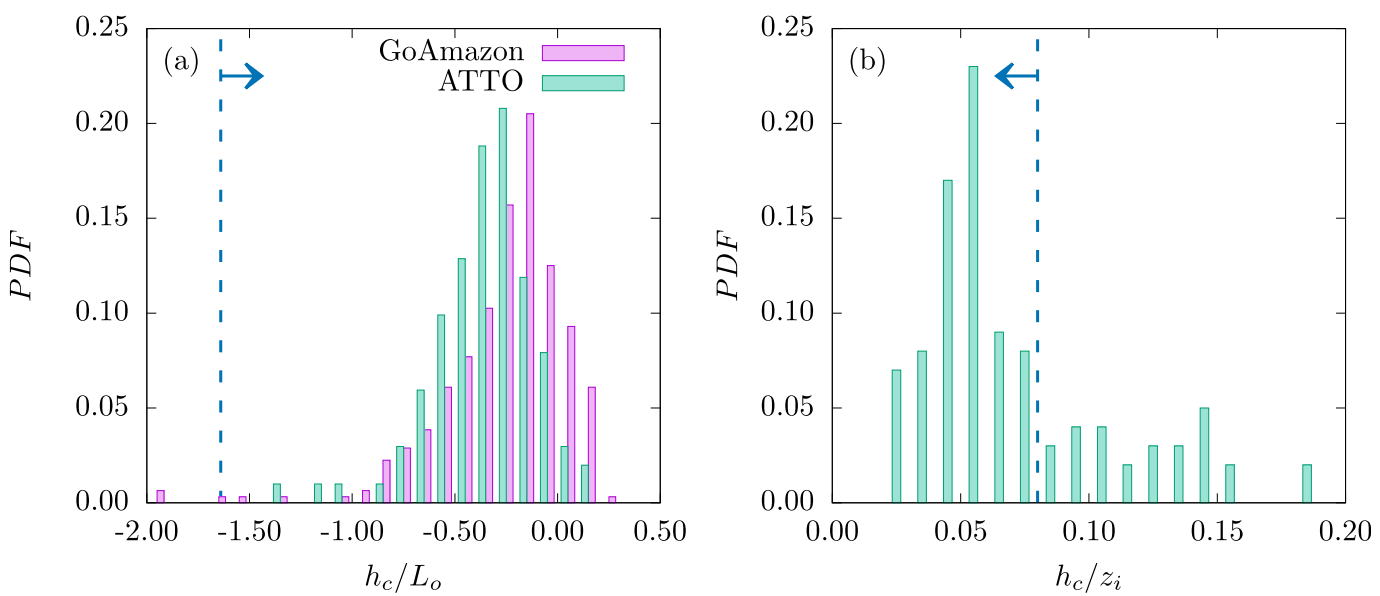

FIG. 5. PDFs of (a) $h_{c} / L_{o}$ and (b) $h_{c} / z_{i}$ for GoAmazon and ATTO field campaigns. Dashed lines indicate criteria given by Eqs. (5) and (6) with $\alpha=0.78$. Blue arrows indicate the direction corresponding to data satisfying each criterion.

in both cases, the local imbalance remains positive within the layer $h_{c} \leq z \leq 0.5 z_{i}$, and for observations made above the canopy top we only anticipate a negative imbalance in the upper portion of the mixed layer, above $z / z_{i} \approx 0.5$.

\section{b. Observations from the Amazon}

As a starting point, we tested the criteria for the existence of the ISL in the GoAmazon and ATTO datasets. Discrete probability distribution functions (discrete PDFs) for $h_{c} / L_{o}$ and $h_{c} / z_{i}$ are shown in Fig. 5 together with lines corresponding to the right-hand sides of Eqs. (5) and (6) obtained with $\alpha=0.78$ (estimates of $z_{i}$ were not available for the GoAmazon campaign). Because some of the near neutral blocks (as identified by the criterion based on $R i_{f}$ ) had positive values of $L_{o}$, we displayed the PDF for $h_{c} / L_{o}$ instead of $h_{c} /\left|L_{o}\right|$, and interpreted the condition given by Eq. (5) as $h_{c} / L_{o} \geq-1.64$. Note that the results shown in Fig. 5a were obtained for the periods in which measurements at canopy top were available. For the GoAmazon dataset, $99 \%$ of the blocks had $h_{c} / L_{o} \geq-1.64$ (Fig. 5a) and, based on this criterion, should have at least a shallow ISL. However, this ISL must be located above $z=2 h_{c}=70 \mathrm{~m}$, and thus above the highest measurement during the field campaign (located at $z=48.2 \mathrm{~m}$ ). Thus, we anticipate that all measurements from the GoAmazon campaign would be within the RSL.

The data from the ATTO site were more interesting in this respect, both because estimates of $z_{i}$ were available and because there were measurements above the RSL, up to $z=8.8 h_{c}$. Interestingly, we found that only about $5 \%$ of the blocks had $z_{i}|| L_{o} \mid>20$, corresponding to the regime dominated by convective cells (and only 19\% had $z_{i} /\left|L_{o}\right|>10$ ). This predominance of forced convection with roll structure was likely associated with the fact that a large fraction of the available net radiation was consumed by evapotranspiration [as an example, see Fig. 5 in Fuentes et al. (2016)], promoting lower values of $z_{i}|| L_{o} \mid$. As a consequence, the criterion based on $z_{i}$ was more restrictive, and $99 \%$ of the blocks satisfied $h_{c} / L_{o} \geq-1.64$ but only $70 \%$ satisfied $h_{c} / z_{i} \leq 0.08$. Based on these two criteria, $33 \%$ of the periods from ATTO had no inertial layer, $40 \%$ should have had a layer that was less than $30 \mathrm{~m}$ deep, and only $27 \%$ of the blocks should have an ISL with depth between 30 and $100 \mathrm{~m}$. For the ATTO site, the RSL extended up to $z=$ $2 h_{c}=74 \mathrm{~m}$, and roughly $60 \%$ of the measurements at $81 \mathrm{~m}$ should have been within the ISL. As for the measurements at $150 \mathrm{~m}$, we expected only about $6 \%$ to be within the ISL.

With this information, an expected pattern arose for the measurements from the two Amazon campaigns. In the GoAmazon, we expected to see RSL behavior influenced by buoyancy at all three heights, with a large positive imbalance at the first height approaching local equilibrium as height increased. For the ATTO campaign, we anticipated similar behavior at the lowest two heights. At $81 \mathrm{~m}$, we expected to see the ISL in at least $50 \%$ of the blocks. The two upper heights were mostly above the ISL if one existed, and we anticipated to see mostly mixed layer behavior. However, data from the two campaigns displayed on the reduced TKE phase space (Figs. 6 and 7) did not conform to these expectations.

We start by discussing the GoAmazon results. Despite the very large spread of points in the phase space, the signature of the RSL with positive imbalance (points 

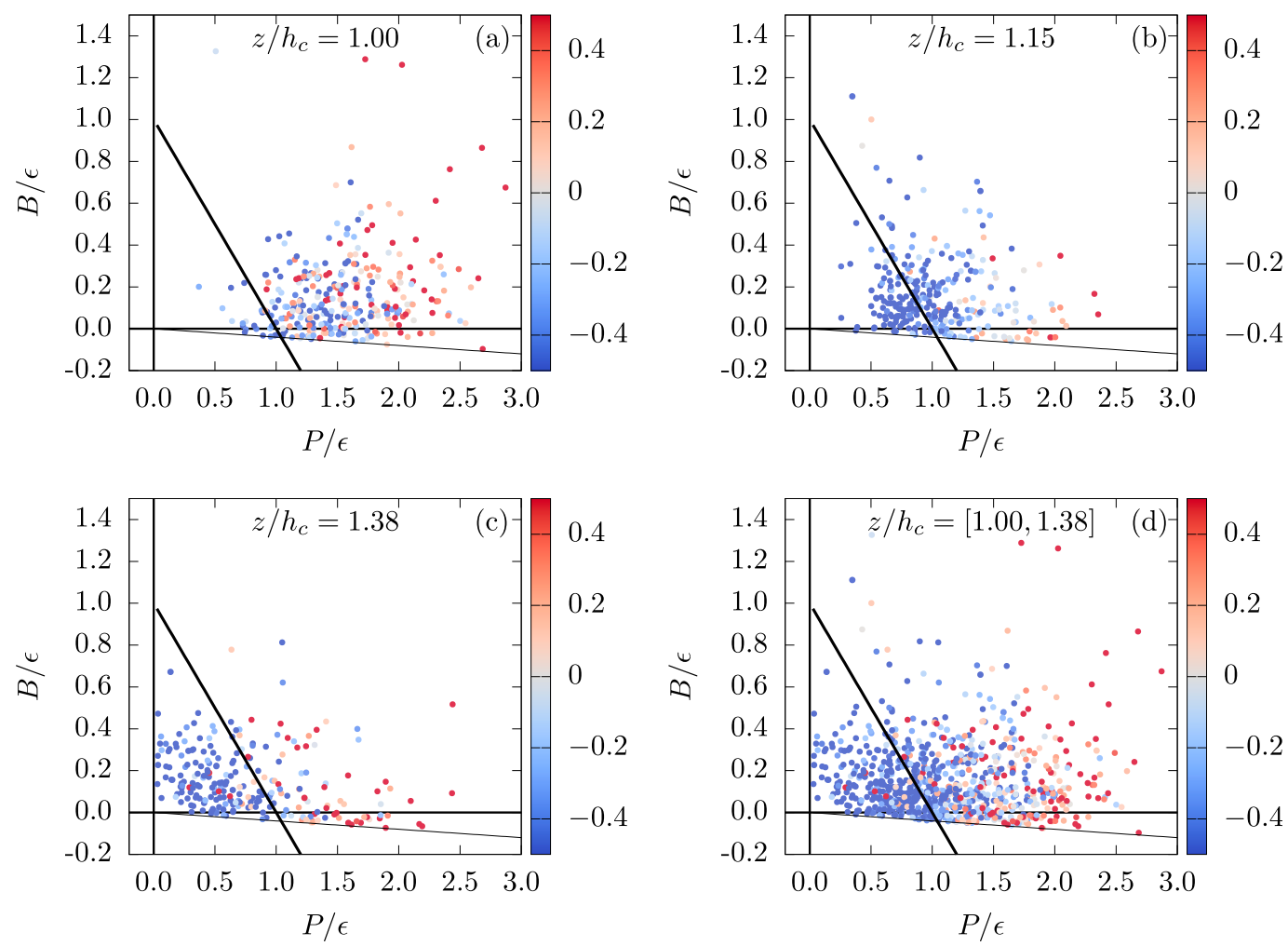

FIG. 6. Data from GoAmazon for (a) $z=34.9 \mathrm{~m}, z / h_{c}=1.00$; (b) $z=40.4 \mathrm{~m}, z / h_{c}=1.15$; and (c) $z=48.2 \mathrm{~m}$, $z / h_{c}=1.38$. (d) Data from all heights together. Points are colored based on $R^{h} / \varepsilon$, a proxy for the importance of deviations from horizontal homogeneity to the TKE budget.

above the local balance line) was clear for measurements at $z / h_{c}=1.00$ (Fig. 6a). However, measurements at $z / h_{c}=$ 1.15 (Fig. 6b) spread around the line of local balance between production and dissipation, suggesting a very fast approach to ISL behavior (one would still expect a fairly large positive imbalance this close to the canopy top). Finally, measurements at $z / h_{c}=1.38$ (Fig. 6c) were quite puzzling given the predominance of points with negative imbalance (points below the local balance line). When all heights were displayed together (Fig. 6d), the points occupied a much larger area of the phase space than in typical ISL measurements (contrast Fig. 6d and Fig. 3a). In all panels in Fig. 6, the points were colored by $R^{h} / \varepsilon$, indicating that the TKE budget was impacted by significant departures from horizontal homogeneity. Note that the predominant behavior with $R^{h}<0$ implied that the effects of heterogeneity were mostly acting as an effective source of local TKE (recall that $R<0$ implies local production smaller than dissipation, and transport must provide the extra energy needed to close the budget). Thus, the color pattern in the phase space was sensible: points with $(P+B) / \varepsilon<1$ had $R^{h}<0$, suggesting that horizontal heterogeneity was, at least in part, responsible for providing the extra energy necessary to close the budget (one must be careful with this interpretation, though, because it does not include the effects of $R^{v}$ ).

The three lowest measurement heights from ATTO displayed a very similar pattern to the GoAmazon results, except that the observations were at significantly different heights $z / h_{c}$. This suggested that the patterns observed were consistent across sites, but that a different length scale (other than $h_{c}$ ) was required to collapse the data. In particular, a layer with negative imbalance was clearly seen at $z / h_{c}=2.19$ (Fig. 7c), where we had anticipated a dominant presence of ISL behavior. While data from $z / h_{c}=4.05$ (Fig. 7d) also showed more deviations from ISL behavior than expected, the highest set of measurements in Fig. 7e were a bit more as expected from observations in the middle of the CBL. Note that at the two top heights, blocks with smaller deviations from horizontal homogeneity tended to conform more with mid-CBL expectations.

Before moving on to explain these deviations, we sought a more concise characterization of the TKE budgets (Fig. 8). To reduce the effect of outliers on the statistics, we present results in terms of median values and 25 th and 75 th percentiles. Without proper normalization, 

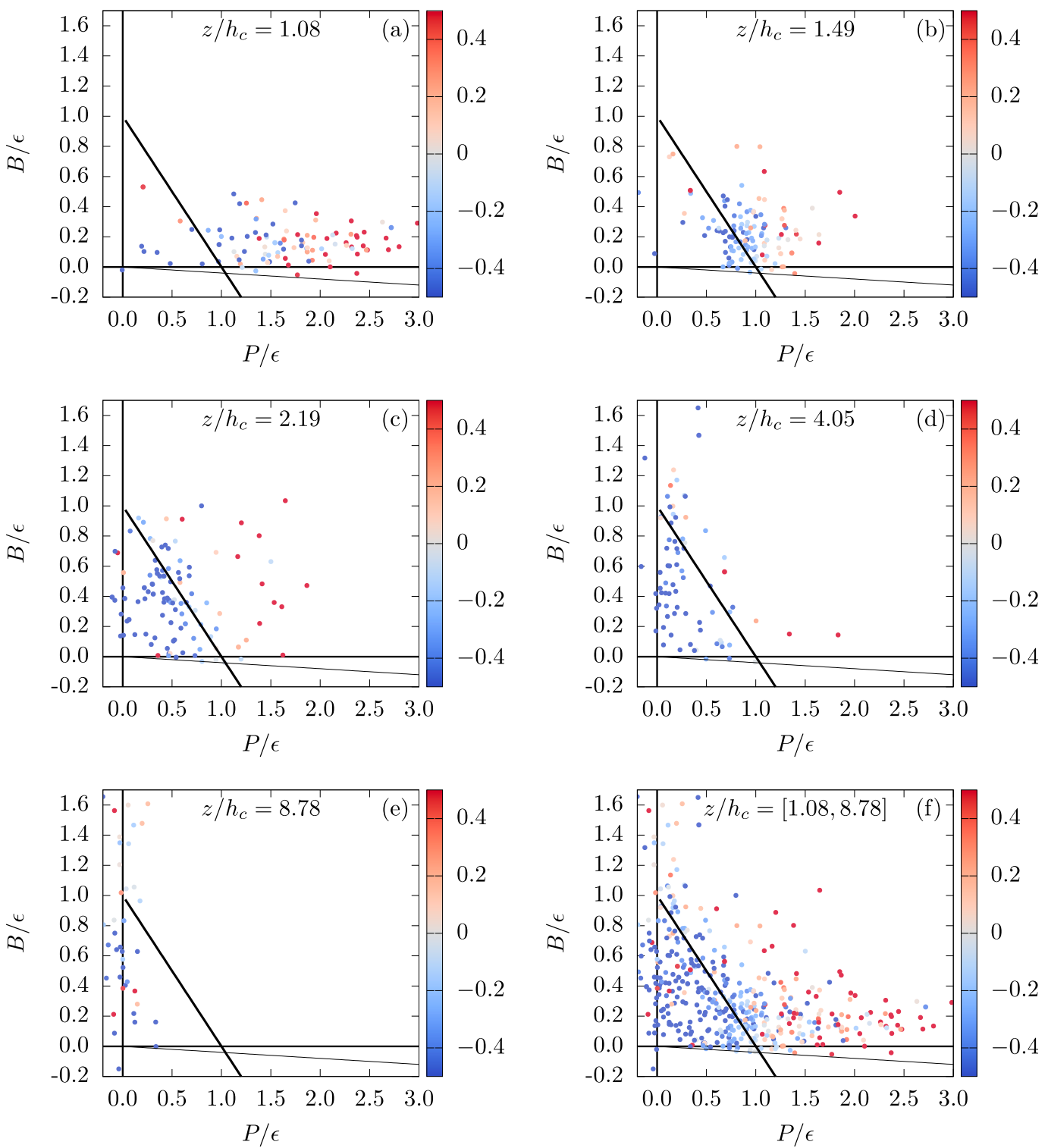

FIG. 7. Data from ATTO for (a) $z=40 \mathrm{~m}, z / h_{c}=1.08$; (b) $z=55 \mathrm{~m}, z / h_{c}=1.49$; (c) $z=81 \mathrm{~m}, z / h_{c}=2.19$; (d) $z=$ $150 \mathrm{~m}, z / h_{c}=4.05$; and (e) $z=325 \mathrm{~m}, z / h_{c}=8.78$. (f) Data from all heights together. Points are colored based on $R^{h} / \varepsilon$, a proxy for the importance of deviations from horizontal homogeneity to the TKE budget.

the profiles of TKE (Fig. 8a) did not show any clear patterns. However, a clear shift in the sign of the vertical flux of TKE (Fig. 8b) was observed in the interval $1.15<z / h_{c}<1.38$ (both limiting points were from the GoAmazon campaign). Note that independent determination of the height at which the flux changed sign for each experiment would have yielded similar results. The downward flux of TKE closer to the canopy was consistent with RSL expectations (see Fig. 1b), while the upward flux above was consistent with CBL expectations (see Fig. 1a). However, the transition occurred much closer to the canopy than one would have anticipated. Note also that the transition from downward to upward flux of TKE in both campaigns corresponded approximately to the unexpected ISL behavior in the TKE phase space with points scattering around the $R=0$ line.

At first sight, the TKE budget (Fig. 8c) confirmed our expectations: the RSL was dominated by shear production and vertical transport of TKE, with only small buoyancy effects, while above the RSL buoyancy became the dominant production mechanism. The net transport was always a sink of TKE in this region, with the exception of a few points in the uppermost sonic 

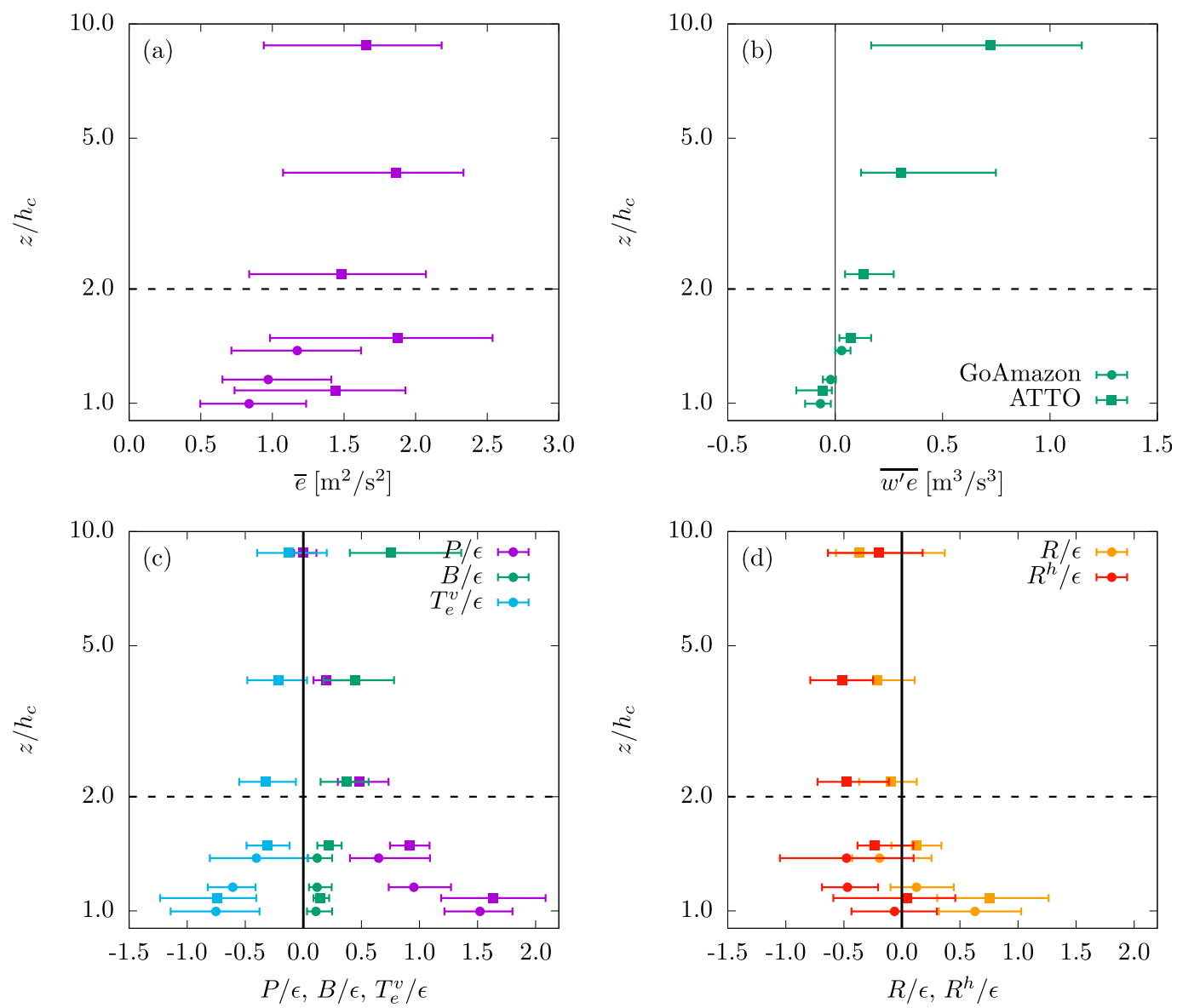

FIG. 8. Profiles of (a) TKE, (b) vertical turbulent flux of TKE, (c) terms in the TKE budget, and (d) contributions to the residual based on data from GoAmazon (circles) and ATTO (squares). Symbols indicate median values and error bars indicate 25 th and 75 th percentiles.

(which was sometimes in the upper portion of the CBL). As indicated by the TKE phase spaces, the unexpected behavior manifested itself in the nature of the local imbalance between production and dissipation. Note that the points displayed in Fig. $8 \mathrm{c}$ are median values, and as such, the median local imbalance $R$ cannot be calculated from the median of the $P$ and $B$. Thus, median values for the local imbalance $R$ and for its horizontal component $R^{h}$ are shown in Fig. 8d. Both in the RSL and in the lower half of the CBL, one would have expected the residual $R / \varepsilon$ to be always positive and approximately equal to the negative of the vertical turbulent transport term (i.e., $R / \varepsilon \approx-T_{e}^{v} / \varepsilon$ ). This was the case only at the lowest measurement height near the canopy top in each campaign, where $R^{h}$ was small (lowest circle and lowest square in Fig. 8d).

For the two heights that had a behavior similar to that expected for ISL on the phase space (Figs. 6b and 7b), we indeed observed $R \approx 0$ (second lowest circle and second lowest square in Fig. 8d). However, we noted that $T_{e}^{v}$ was large at these heights (Fig. 8c), requiring a similarly large $R^{h}$. This did not conform with true ISL behavior, suggesting that the behavior on the phase space was deceiving. For the upper sonics, $-T_{e}^{v}$ had the opposite sign of $R$, implying large deviations from $R \approx-T_{e}^{v}$ that must be balanced by large $R^{h}$. Thus, main deviations from local balance were not due to vertical transport, but rather associated with deviations from horizontal homogeneity. In this sense, the picture that emerges from Figs. 6-8 suggests a flow in which horizontal heterogeneity has a dominant imprint on the TKE budget. For these two specific sites (and for most of the Amazon forest), the two main possible causes of deviations from horizontal homogeneity are the presence of topography and the horizontal variation in canopy structure. In the Amazon forest, vegetation in the valleys tend to be shorter and less dense than in the plateaus, due to the larger fraction of sand in the soil (Da Silva et al. 2002). Because we believe the effect of topography to be significantly more important than that of 


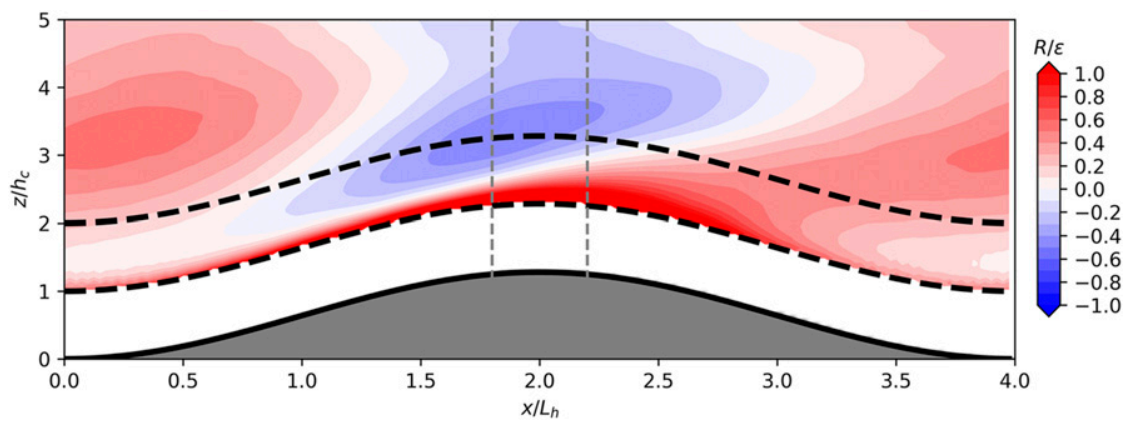

FIG. 9. Normalized local imbalance of TKE $R / \varepsilon$ above the canopy from LES of the Amazon forest over idealized topography. The two thick black dashed lines indicate $z / h_{c}=1$ and $z / h_{c}=2$, where $z$ is the vertical distance measured from the ground surface. The two vertical gray dashed lines indicate the region $\left(x / L_{h}\right)=2 \pm 0.2$, which is used here to define the "top of the ridge."

forest heterogeneity, we investigate this in the next section.

\section{c. Effects of idealized topography on TKE budget}

Here our goal was not to perform a complete investigation of TKE budgets over forested topography, but rather to use existing LES results to investigate if topography could explain the overall patterns in the TKE budget from the observations described in the previous section. To gain some insight on the effects of topography on the local balance of TKE production and dissipation, we looked at $R / \varepsilon=P / \varepsilon-1$ over the idealized hill covered by a model of the Amazon forest under neutral stratification. Results from the LES run described in section $3 b$ are displayed in Fig. 9. The strong effect of the topography on the TKE budget within the RSL (roughly between the two black dashed lines) is clearly seen in the figure. Note that, contrary to the situation over flat topography, portions of the RSL had strongly negative local imbalance. In particular, in the region at the top of the ridge (representative of the plateaus in the Amazon forest, where measurements were made for both campaigns), a fairly complex pattern was present in which a transition from positive to negative imbalance occurred within the RSL.

To draw a more direct comparison between the measurements in the Amazon and the LES results for idealized topography, LES data from the region $\left(x / L_{h}\right)=$ $2 \pm 0.2$ considered for practical purposes as the top of the ridge are shown in Fig. 10a together with results for LES over flat topography (i.e., results from the LES shown in Fig. 3b). In comparison to the flat case, the presence of topography produced a much larger range of possibilities in terms of local imbalance of TKE. If we confine our observations to the top of the ridge, then the overall effect was to increase the positive imbalance in the lower half of the RSL and to reduce it in the upper half. This reduction was large enough to produce a region of negative imbalance in the upper part of the RSL. Effects of topography seemed to extend above $z / h_{c}=4$ (above this height simulations results were impacted by the numerical boundary conditions at the top of the domain and were not analyzed). These conclusions are specific to the simple topography employed in the simulation, and to the specific combination of vegetation and topography scales used in this specific case. Nevertheless, the simulation did show that topographic effects can be quite strong and produce results at the top of the hill that were consistent with the observations in the previous section. This becomes clear when profiles of normalized imbalance are put side to side as done in Fig. 10. The major differences between the profiles from observation and LES are likely caused by the differences in topography and the absence of static stability effects in the simulation. However, the clear existence of a region with negative imbalance in the upper part of the RSL after a transition region with $R \approx 0$ in both, LES and observations, can be explained by the presence of topography.

To guide the interpretation of these results, we used the theoretical work on neutral flows over rough isolated hills developed by Hunt et al. (1988). In this theory, valid for small hills, the inner layer is defined as the region where $z / h_{i} \leq 1$, with $h_{i}$ implicitly defined via

$$
\frac{h_{i}}{L_{h}} \ln \left(\frac{h_{i}}{z_{0}}\right)=2 \kappa^{2} .
$$

In the lower half of the inner layer, eddy lifetime $\left(\tau_{\epsilon}=\bar{e} / \varepsilon\right)$ is small compared to the advection time scale $\left(\tau_{a}=L_{h} / \bar{u}\right)$, so eddies do not last long enough to experience significant changes in straining rate. In this region, turbulence is approximately homogeneous, turbulent transport and advection of TKE are small 

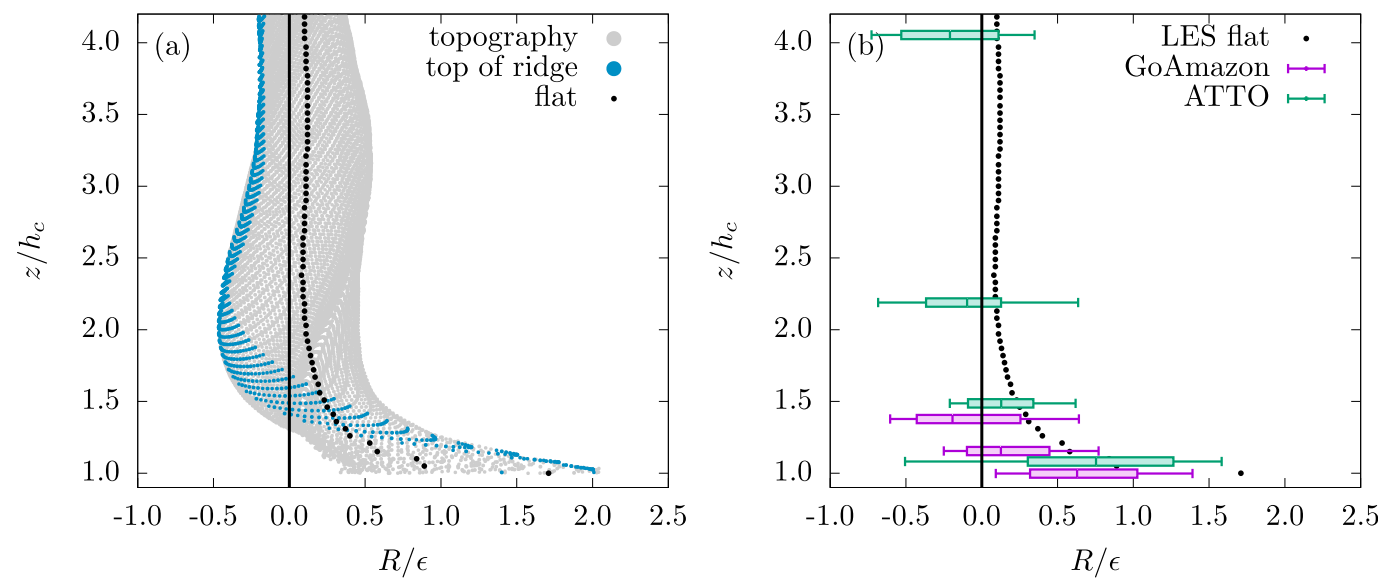

FIG. 10. Vertical profiles of normalized local imbalance $(R / \varepsilon)$ for (a) LES of flow above canopy and (b) observations from Amazon. In (a), black circles are for the horizontal homogeneous case over flat terrain, gray dots are for the forest over topography, and magenta dots are a subset of the gray dots at the top of the ridge [here defined as $\left.\left(x / L_{h}\right)=2 \pm 0.2\right]$. In (b), lines indicate the median, boxes indicate the 25th and 75th percentiles, and whiskers indicate 10 th and 90 th percentiles.

and there must be an approximate balance between production and dissipation of TKE (Belcher et al. 1993; Kaimal and Finnigan 1994). Thus, one would expect $R \approx$ 0 . For forest covered hills, the inner layer is the region within $d_{0} \leq z \leq\left(d_{0}+h_{i}\right)$, and it would be natural to expect the local balance in the lower half of the inner layer to be broken by vertical transport of TKE into the canopy (i.e., $R^{v}>0$ but $R^{h} \approx 0$ ).

Using the roughness length $z_{0}=2 \mathrm{~m}$ estimated from GoAmazon data and the values of $L_{h}$ estimated from the topography map (Fig. 2), Eq. (7) yielded $h_{i}=40 \mathrm{~m}$ for the GoAmazon and $h_{i}=55 \mathrm{~m}$ for the ATTO site. The profiles of the two time scales $\tau_{\varepsilon}$ and $\tau_{a}$ are shown in
Fig. 11a, where the gray region corresponds to the inner layer for the ATTO site (for the GoAmazon, the inner layer was slightly shallower). The ratio between the two time scales is also shown in Fig. 11b, and it was in agreement with the expectations for flow over rough hills, in the sense that $\tau_{\varepsilon} / \tau_{a}<1$ within the inner layer and $\tau_{\varepsilon} / \tau_{a}>1$ above.

However, our analysis suggests that the causes for local imbalance within the inner layer extends beyond the vertical transport characteristic of flow over canopies. LES results show strong horizontal variability in the local imbalance (Fig. 9). In addition, analysis of observations suggests that vertical transport can only
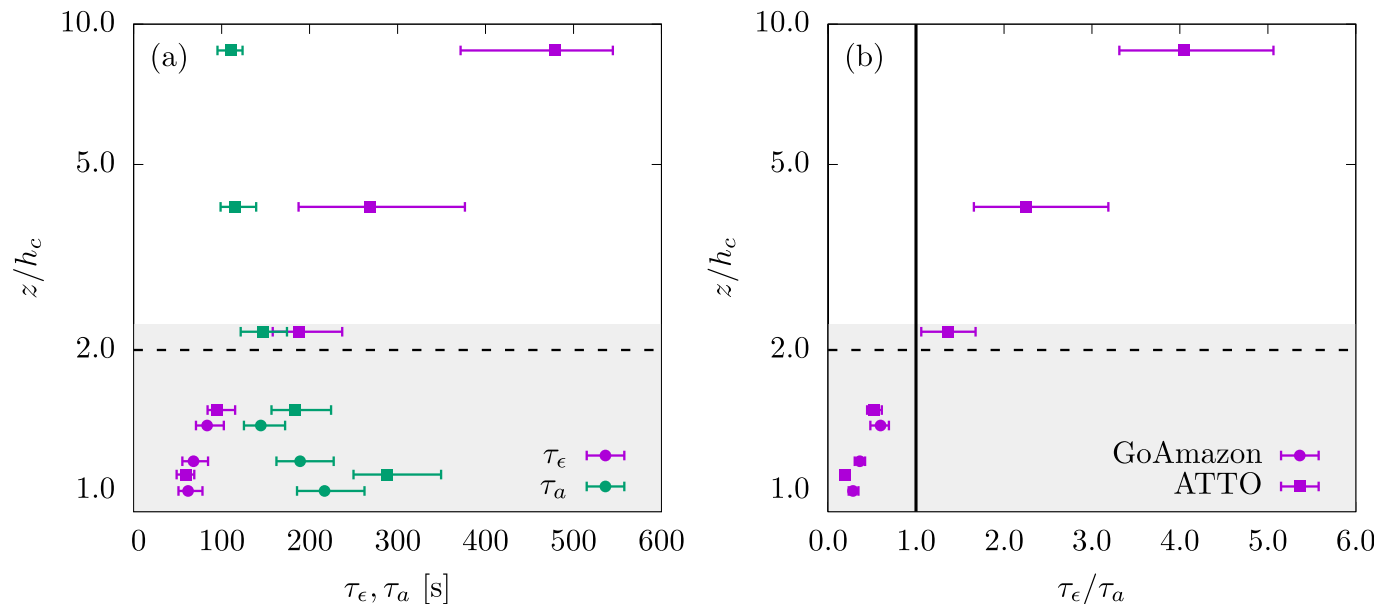

FIG. 11. (a) Profiles of eddy turnover time scale $\left(\tau_{\varepsilon} ;\right.$ blue) and advection time scale $\left(\tau_{a}\right.$; red), and (b) ratio between time scales $\tau_{\varepsilon} / \tau_{a}$. Dashed line at $z / h=2$ indicates the end of the RSL over flat terrain and the gray region indicates the inner layer for flow over topography estimated for the ATTO site (for the GoAmazon, the inner layer is slightly shallower). 
explain the local imbalance very close to the canopy top $\left(z / h_{c}=1.00\right.$ and $z / h_{c}=1.08$ for GoAmazon and ATTO, respectively). At $z / h_{c}=1.15$ for the GoAmazon data, which is well within the inner layer, the importance of deviations from horizontal homogeneity are quite strong (Fig. 8b). Together, these points suggest that advection and/or horizontal transport by pressure and velocity fluctuations play a very important role within the inner layer over vegetated topography. A more detailed analysis of LES results is needed to confirm the role of advection.

\section{Conclusions}

The goal of the present paper was to characterize the structure of the ABL over gentle topography covered by forests using daytime observations from two field campaigns in central Amazonia. We used an analysis of the TKE budget on the reduced TKE phase space (Chamecki et al. 2018), focusing on the local imbalance between production and dissipation. To facilitate interpretation, the imbalance was also split into a portion consistent with horizontal homogeneity and a portion caused by horizontal heterogeneity. The interpretation of the observational results was aided by LESs.

Analysis on the TKE phase space revealed two striking features in the observations: 1) a region in approximate local balance between production and dissipation, akin to an inertial sublayer, located fairly close to the canopy top $\left(z / h_{c}=1.15\right.$ for GoAmazon and $z / h_{c}=1.49$ for ATTO $)$, and 2) a region with local production smaller than dissipation still within the roughness sublayer $\left(z / h_{c}=1.38\right.$ for GoAmazon and $z / h_{c}=2.19$ for ATTO). Neither can be explained by the canonical flat-terrain TKE budgets in the canopy roughness sublayer or in the lower portion of the convective ABL. Both layers were characterized by a negative net transport of TKE, as expected from a roughness sublayer behavior, and our analysis showed that deviations from horizontal homogeneity in these layers were remarkably large. Results from LES of a model canopy over idealized (but comparable) topography suggested that the presence of topography can explain the behavior of the TKE budget in these two regions. Thus, we concluded that the boundary layer above the Amazon forest is strongly impacted by the gentle topography underneath, and that topography explains the patterns of TKE imbalance reported by Chamecki et al. (2018).

Our analysis confirmed the observation from DiasJúnior et al. (2019) that there is no inertial sublayer at the ATTO site, and extended this observation to the GoAmazon site as well. We derived two criteria for the existence of an ISL over forests in flat terrain, and most of the data satisfied these criteria, suggesting that an ISL should exist in the absence of topography. Based on this fact, and on the characteristics of the TKE budget, we concluded that most of the time there is a layer between the canopy roughness sublayer and the mixed layer above. Over flat terrain, we would expect MOST to hold in this layer. However, the horizontal flow heterogeneity produced by the presence of topography modifies the TKE budget, producing more complex turbulence that does not conform to MOST.

If one were to think about the topography as a "largescale roughness" (e.g., from a mesoscale perspective), then the layer in which the topography produces major modifications in the flow would be the roughness sublayer associated with the topography itself. From this viewpoint, there are two roughness sublayers superimposed on (and interacting with) each other: the roughness sublayer associated with the forest and the one associated with the topography.

Several questions remain, and an LES investigation of the TKE budget above forests in complex terrain under various atmospheric stability conditions is probably warranted. Our analysis also reviewed some interesting features of the TKE budget in the inner layer of the flow over topography, that seemed to differ from the behavior for flow over rough hills. In particular, the striking spatial variability of the TKE imbalance seems to question some of the assumptions employed in the analysis of rough hills and ridges. A better characterization of the TKE budget in this region is needed. From an observational perspective, it would be useful to confirm that at the top of ridges, shear production can still be accurately estimated from the vertical shear in the streamwise velocity, and that the other components are still small. It would also be useful to quantify the effects of pressure transport, to solidify the data analysis framework developed here.

Acknowledgments. MC is grateful for funding provided by the Federal University of Parana in the form of a visiting professorship during the months of July and August 2019. MC and BC were funded by the National Science Foundation (Grant AGS-1644375). NLD was funded by CNPq's Research Scholarship 301420/2017-3. LF was funded by São Paulo Research Foundation (FAPESP, Brazil) Grant 2018/24284-1. The U.S. Department of Energy supported the field studies as part of the GoAmazon 2014/5 project (Grant SC0011075), together with FAPESP and FAPEAM. We thank the Max Planck Society and the Instituto Nacional de Pesquisas da Amazônia for continuous support. We acknowledge the support by the German Federal Ministry of Education and Research (BMBF Contract 01LB1001A) and the Brazilian Ministério 
da Ciência, Tecnologia e Inovação (MCTI/FINEP Contract 01.11.01248.00) as well as the Amazon State University (UEA), FAPEAM, LBA/INPA and SDS/CEUC/RDS405 Uatumã. The processed data needed for reproducing the figures are available from the authors upon request (chamecki@ucla.edu).

\section{REFERENCES}

Arnqvist, J., A. Segalini, E. Dellwik, and H. Bergström, 2015: Wind statistics from a forested landscape. Bound-Layer Meteor., 156, 53-71, https://doi.org/10.1007/s10546-015-0016-x.

Baldocchi, D., 2008: 'Breathing' of the terrestrial biosphere: Lessons learned from a global network of carbon dioxide flux measurement systems. Aust. J. Bot., 56, 1-26, https://doi.org/ 10.1071/BT07151.

_ J. Finnigan, K. Wilson, K. T. Paw U, and E. Falge, 2000: On measuring net ecosystem carbon exchange over tall vegetation on complex terrain. Bound.-Layer Meteor., 96, 257-291, https://doi.org/10.1023/A:1002497616547.

—- and Coauthors, 2001: FLUXNET: A new tool to study the temporal and spatial variability of ecosystem-scale carbon dioxide, water vapor, and energy flux densities. Bull. Amer. Meteor. Soc., 82, 2415-2434, https://doi.org/10.1175/15200477(2001)082<2415:FANTTS > 2.3.CO;2.

Belcher, S. E., T. M. J. Newley, and J. C. R. Hunt, 1993: The drag on an undulating surface induced by the flow of a turbulent boundary layer. J. Fluid Mech., 249, 557-596, https://doi.org/ 10.1017/S0022112093001296.

— I. N. Harman, and J. J. Finnigan, 2012: The wind in the willows: Flows in forest canopies in complex terrain. Annu. Rev. Fluid. Mech., 44, 479-504, https://doi.org/10.1146/annurevfluid-120710-101036.

Brunet, Y., J. Finnigan, and M. Raupach, 1994: A wind tunnel study of air flow in waving wheat: Single-point velocity statistics. Bound.-Layer Meteor., 70, 95-132, https://doi.org/10.1007/ BF00712525.

Businger, J. A., J. C. Wyngaard, Y. Izumi, and E. F. Bradley, 1971: Flux-profile relationships in the atmospheric surface layer. J. Atmos. Sci., 28, 181-189, https://doi.org/10.1175/15200469(1971)028<0181:FPRITA > 2.0.CO;2.

Cellier, P., and Y. Brunet, 1992: Flux-gradient relationships above tall plant canopies. Agric. For. Meteor., 58, 93-117, https:// doi.org/10.1016/0168-1923(92)90113-I.

Chamecki, M., and N. L. Dias, 2004: The local isotropy hypothesis and the turbulent kinetic energy dissipation rate in the atmospheric surface layer. Quart. J. Roy. Meteor. Soc., 130, 2733-2752, https://doi.org/10.1256/qj.03.155.

,,-- S. T. Salesky, and Y. Pan, 2017: Scaling laws for the longitudinal structure function in the atmospheric surface layer. J. Atmos. Sci., 74, 1127-1147, https://doi.org/10.1175/ JAS-D-16-0228.1.

—_, —_, and L. S. Freire, 2018: A TKE-based framework for studying disturbed atmospheric surface layer flows and application to vertical velocity variance over canopies. Geophys. Res. Lett., 45, 6734-6740, https://doi.org/10.1029/ 2018 GL077853.

Chen, B., M. Chamecki, and G. G. Katul, 2019: Effects of topography on in-canopy transport of gases emitted within dense forests. Quart. J. Roy. Meteor. Soc., 145, 2101-2114, https:// doi.org/10.1002/qj.3546.
,-- , and -2020 : Effects of gentle topography on forestatmosphere gas exchanges and implications for eddy-covariance measurements. J. Geophys. Res. Atmos., 125, e2020JD032581, https://doi.org/10.1029/2020JD032581.

Chor, T. L., and Coauthors, 2017: Flux-variance and flux-gradient relationships in the roughness sublayer over the amazon forest. Agric. For. Meteor., 239, 213-222, https://doi.org/10.1016/ j.agrformet.2017.03.009.

— J. McWilliams, and M. Chamecki, 2020: Diffusive-nondiffusive flux decomposition in atmospheric boundary layers. J. Atmos. Sci., submitted.

da Silva, R. P., J. dos Santos, E. S. Tribuzy, J. Q. Chambers, S. Nakamura, and N. Higuchi, 2002: Diameter increment and growth patterns for individual tree growing in central Amazon, Brazil. For. Ecol. Manage., 166, 295-301, https://doi.org/10.1016/ S0378-1127(01)00678-8.

Dias-Júnior, C. Q., and Coauthors, 2019: Is there a classical inertial sublayer over the Amazon forest? Geophys. Res. Lett., 46, 5614-5622, https://doi.org/10.1029/2019GL083237.

Dupont, S., Y. Brunet, and J. Finnigan, 2008: Large-eddy simulation of turbulent flow over a forested hill: Validation and coherent structure identification. Quart. J. Roy. Meteor. Soc., 134, 1911-1929, https://doi.org/10.1002/qj.328.

Dwyer, M. J., E. G. Patton, and R. H. Shaw, 1997: Turbulent kinetic energy budgets from a large-eddy simulation of airflow above and within a forest canopy. Bound.-Layer Meteor., 84, 23-43, https://doi.org/10.1023/A:1000301303543.

Earth Observing Laboratory, 1990: NCAR Integrated Surface Flux System (ISFS). UCAR/NCAR, https://doi.org/10.5065/ D6ZC80XJ.

Farr, T. G., and Coauthors, 2007: The Shuttle Radar Topography Mission. Rev. Geophys., 45, RG2004, https://doi.org/10.1029/ 2005RG000183.

Feigenwinter, C., L. Montagnani, and M. Aubinet, 2010: Plotscale vertical and horizontal transport of $\mathrm{CO}_{2}$ modified by a persistent slope wind system in and above an Alpine forest. Agric. For. Meteor., 150, 665-673, https://doi.org/10.1016/ j.agrformet.2009.05.009.

Fernando, H., and Coauthors, 2019: The Perdigao: Peering into microscale details of mountain winds. Bull. Amer. Meteor. Soc., 100, 799-819, https://doi.org/10.1175/BAMS-D-17-0227.1.

Finnigan, J., and S. Belcher, 2004: Flow over a hill covered with a plant canopy. Quart. J. Roy. Meteor. Soc., 130, 1-29, https:// doi.org/10.1256/qj.02.177.

Fisch, G., J. Tota, L. Machado, M. S. Dias, R. F. Lyra, C. Nobre, A. Dolman, and J. Gash, 2004: The convective boundary layer over pasture and forest in Amazonia. Theor. Appl. Climatol., 78, 47-59, https://doi.org/10.1007/s00704-004-0043-x.

Freire, L. S., and Coauthors, 2017: Turbulent mixing and removal of ozone within an Amazon rainforest canopy. J. Geophys. Res. Atmos., 122, 2791-2811, https://doi.org/10.1002/2016JD026009.

—, M. Chamecki, E. Bou-Zeid, and N. L. Dias, 2019a: Critical flux Richardson number for Kolmogorov turbulence enabled by TKE transport. Quart. J. Roy. Meteor. Soc., 145, 1551-1558, https://doi.org/10.1002/qj.3511.

— N. L. Dias, and M. Chamecki, 2019b: Effects of path averaging in a sonic anemometer on the estimation of turbulencekinetic-energy dissipation rates. Bound.-Layer Meteor., 173, 99-113, https://doi.org/10.1007/s10546-019-00453-4.

Fuentes, J. D., and Coauthors, 2016: Linking meteorology, turbulence, and air chemistry in the Amazon rain forest. Bull. Amer. Meteor. Soc., 97, 2329-2342, https://doi.org/10.1175/BAMS-D15-00152.1. 
Ghannam, K., G. G. Katul, E. Bou-Zeid, T. Gerken, and M. Chamecki, 2018: Scaling and similarity of the anisotropic coherent eddies in near-surface atmospheric turbulence. J. Atmos. Sci., 75, 943-964, https://doi.org/10.1175/JAS-D-17-0246.1.

Grant, E. R., A. N. Ross, B. A. Gardiner, and S. D. Mobbs, 2015: Field observations of canopy flows over complex terrain. Bound.-Layer Meteor., 156, 231-251, https://doi.org/10.1007/ s10546-015-0015-y.

Harman, I. N., and J. J. Finnigan, 2007: A simple unified theory for flow in the canopy and roughness sublayer. Bound.-Layer Meteor., 123, 339-363, https://doi.org/10.1007/s10546-006-9145-6.

Högström, U., 1988: Non-dimensional wind and temperature profiles in the atmospheric surface layer: A re-evaluation. Bound.-Layer Meteor., 42, 55-78, https://doi.org/10.1007/BF00119875.

_ 1990: Analysis of turbulence structure in the surface layer with a modified similarity formulation for near neutral conditions. J. Atmos. Sci., 47, 1949-1972, https://doi.org/10.1175/ 1520-0469(1990)047<1949:AOTSIT>2.0.CO;2.

Hunt, J., S. Leibovich, and K. Richards, 1988: Turbulent shear flows over low hills. Quart. J. Roy. Meteor. Soc., 114, 14351470, https://doi.org/10.1002/qj.49711448405.

Jackson, P. S., 1981: On the displacement height in the logarithmic velocity profile. J. Fluid Mech., 111, 15-25, https://doi.org/ 10.1017/S0022112081002279.

Kaimal, J. C., and J. J. Finnigan, 1994: Atmospheric Boundary Layer Flows: Their Structure and Measurement. Oxford University Press, 289 pp.

Kolmogorov, A. N., 1941: The local structure of turbulence in incompressible viscous fluid for very large Reynolds numbers. Dokl. Akad. Nauk SSSR, 30, 299-303.

Kruijt, B., Y. Malhi, J. Lloyd, A. Norbre, A. Miranda, M. Pereira, A. Culf, and J. Grace, 2000: Turbulence statistics above and within two Amazon rain forest canopies. Bound.-Layer Meteor., 94, 297-331, https://doi.org/10.1023/A:1002401829007.

Lee, X., 1998: On micrometeorological observations of surface-air exchange over tall vegetation. Agric. For. Meteor., 91, 39-49, https://doi.org/10.1016/S0168-1923(98)00071-9.

Lenschow, D., J. C. Wyngaard, and W. T. Pennell, 1980: Mean-field and second-moment budgets in a baroclinic, convective boundary layer. J. Atmos. Sci., 37, 1313-1326, https://doi.org/10.1175/15200469(1980)037<1313:MFASMB > 2.0.CO;2.

Mahrt, L., 2014: Stably stratified atmospheric boundary layers. Annu. Rev. Fluid. Mech., 46, 23-45, https://doi.org/10.1146/ annurev-fluid-010313-141354.

Malhi, Y., K. McNaughton, and C. Von Randow, 2004: Low frequency atmospheric transport and surface flux measurements. Handbook of Micrometeorology, Springer, 101-118.

Marcolla, B., A. Pitacco, and A. Cescatti, 2003: Canopy architecture and turbulence structure in a coniferous forest. Bound.-Layer Meteor., 108, 39-59, https://doi.org/10.1023/A:1023027709805.

Oliveira, P. E., and Coauthors, 2018: Nighttime wind and scalar variability within and above an Amazonian canopy. Atmos.
Chem. Phys., 18, 3083-3099, https://doi.org/10.5194/acp-183083-2018.

Pan, Y., and M. Chamecki, 2016: A scaling law for the shearproduction range of second-order structure functions. J. Fluid Mech., 801, 459-474, https://doi.org/10.1017/jfm.2016.427.

Patton, E. G., and G. G. Katul, 2009: Turbulent pressure and velocity perturbations induced by gentle hills covered with sparse and dense canopies. Bound.-Layer Meteor., 133, 189217, https://doi.org/10.1007/s10546-009-9427-x.

Poggi, D., G. G. Katul, J. J. Finnigan, and S. E. Belcher, 2008: Analytical models for the mean flow inside dense canopies on gentle hilly terrain. Quart. J. Roy. Meteor. Soc., 134, 10951112, https://doi.org/10.1002/qj.276.

Ross, A. N., 2008: Large-eddy simulations of flow over forested ridges. Bound.-Layer Meteor., 128, 59-76, https://doi.org/ 10.1007/s10546-008-9278-x.

, 2011: Scalar transport over forested hills. Bound.-Layer Meteor., 141, 179-199, https://doi.org/10.1007/s10546-0119628-y.

, and S. Vosper, 2005: Neutral turbulent flow over forested hills. Quart. J. Roy. Meteor. Soc., 131, 1841-1862, https:// doi.org/10.1256/qj.04.129.

Ruck, B., and E. Adams, 1991: Fluid mechanical aspects of the pollutant transport to coniferous trees. Bound.-Layer Meteor., 56, 163-195, https://doi.org/10.1007/BF00119966.

Salesky, S. T., and M. Chamecki, 2012: Random errors in turbulence measurements in the atmospheric surface layer: Implications for Monin-Obukhov similarity theory. J. Atmos. Sci., 69, 3700-3714, https://doi.org/10.1175/JAS-D-12-096.1.

, - $\longrightarrow$, and E. Bou-Zeid, 2017: On the nature of the transition between roll and cellular organization in the convective boundary layer. Bound.-Layer Meteor., 163, 41-68, https:// doi.org/10.1007/s10546-016-0220-3.

Stull, R. B., 1988: An Introduction to Boundary Layer Meteorology. Kluwer Academic, 666 pp.

Tóta, J., D. R. Fitzjarrald, and M. A. F. da Silva Dias, 2012a: Exchange of carbon between the atmosphere and the tropical Amazon rainforest. Sci. World J., 2012, 305-330, https:// doi.org/10.5772/29716.

, — - and - 2012b: Amazon rainforest exchange of carbon and subcanopy air flow: Manaus LBA site-A complex terrain condition. Sci. World J., 2012, 165067, https://doi.org/ 10.1100/2012/165067.

Vickers, D., and L. Mahrt, 1997: Quality control and flux sampling problems for tower and aircraft data. J. Atmos. Oceanic Technol., 14, 512-526, https://doi.org/10.1175/1520-0426(1997) $014<0512$ :QCAFSP $>2.0 . \mathrm{CO} ; 2$

Wilczak, J., S. Oncley, and S. Stage, 2001: Sonic anemometer tilt correction algorithms. Bound.-Layer Meteor., 99, 127-150, https://doi.org/10.1023/A:1018966204465.

Wyngaard, J. C., 2010: Turbulence in the Atmosphere. Cambridge University Press, 405 pp. 